\title{
Identification of nonlinear dynamic behavior and failure for riveted joint assemblies
}

\author{
B. Langrand ${ }^{\mathrm{a}, *}$, E. Deletombe ${ }^{\mathrm{a}}$, \\ E. Markiewicz ${ }^{\mathrm{b}}$ and P. Drazétic ${ }^{\mathrm{b}}$ \\ ${ }^{a}$ ONERA-Lille, Solid and Damage Mechanics \\ Department, Structural Resistance and Design \\ Section, 5, bvd Paul Painlevé, 59045 Lille, France \\ Tel.: +33 320496 900; Fax: +33 320529 593; \\ E-mail: langrand@imf-lille.fr \\ ${ }^{\mathrm{b}}$ Industrial and Human Automatic Control and \\ Mechanical Engineering Laboratory, Mechanical \\ Engineering Research Group (UMR CNRS 8530), \\ University of Valenciennes - Le Mont Houy, B.P. 311, \\ 59304 Valenciennes Cedex, France \\ E-mail: markiewicz@univ-valenciennes.fr
}

Received 10 June 1999

Revised 14 February 2000

\begin{abstract}
Many different types of rivets need to be modeled to analyze the crashworthiness of aircraft structures. A numerical procedure based on FE modeling and characterization of material failure constitutive models is proposed herein with the aim of limiting the costs of experimental procedures otherwise necessary to obtain these data. Quasi-static and dynamic experiments were carried out on elementary tension (punched) and shear (riveted) specimens. No strain rate sensitivity was detected in the failure behavior of the riveted joint assemblies. Experimental data were used to identify the Gurson damage parameters of each material (2024-T351 and 7050 aluminum alloys for the sheet metal plate and the rivet respectively) by an inverse method. Characterization gave rise to satisfactory correlation between FE models and experiments. Optimized parameters were validated for each material by means of a uniaxial tension test for the sheet metal plate and an ARCAN type specimen in pure tension for the rivet.
\end{abstract}

\section{Introduction}

The structure of modern fighter and commercial aircraft includes many assembled parts. These parts have

\footnotetext{
*Corresponding author.
}

more or less complex geometries. They are made of aluminum alloy sheet sections with different functions (e.g. frame, skin, clip), material properties and structural properties (e.g. thickness). They are mainly assembled by rivets. The riveted joint parameters (e.g. number of rivets, edge margin and pitch), are designed to ensure mechanical strength based on calculation rules which depend on the mechanical and geometrical properties of the sheet metal plate and the rivet. Failure to comply with these rules may lead to defects during the riveting process [8]. Such defects lead to assembly embrittlement and must therefore be avoided. These rules mean that a wide range of rivet characteristics must be taken into account for a complete structure:

- Riveted joint parameters (e.g. edge margin a, pitch p)

- Riveted joint type (e.g. row, chain, staggered)

- Rivet type (e.g. mushroom or countersunk head, screwed, shocked or blind rivet).

As part of the crash modeling of aircraft structures, numerous FE developments were undertaken to improve the representation of riveted structures in terms of failure or local dislocation predictions. These riveted structures can be exposed to high stresses and broken. For reasons of CPU time, the behavior of these joints is now simulated by equivalent models. Experimental determination of rivet properties for use in such FE models would lead to an expensive experimental database to take the variety of aeronautical joints into account. To have access to this characterization and limit its experimental cost, a technique based on accurate solid finite element modeling is proposed herein (i.e. the development of a numerical database). This method is based on preliminary characterization of a failure model for the materials composing the assembly (i.e. the sheet metal plate and the rivet). Once the failure model has been characterized, the response of each riveted joint type can be extracted by modeling using the Finite Element (FE) method. This numerical tool allows a user to vary the specimen geometry, the 
loading, the number or type of rivets and therefore to complete the numerical database.

As part of this research, FE modeling of mechanical assemblies under dynamic loading was undertaken with the PAM-CRASH ${ }^{\mathrm{TM}}$ FE code. Characterization tests were performed for different imposed velocities (from quasi-static to dynamic) on simple punched tension specimens (sheet metal plate) and on single lap riveted joint shear specimens (rivet). In this research, the Gurson damage model $[4,10]$ was used to describe the damage behavior of ductile metals such as the two aluminum alloys considered here. The internally developed OPTB2L optimizer [6] was used to identify the parameters of the Gurson model for the 2024-T351 (sheet metal plate) and 7050 (rivet) aluminum alloys by an inverse method. This method consists in finding a large number of solutions of the direct problem so as to determine the system's behavior, which is the unknown in our problem. The solution is found by minimizing the difference between the experimental response, considered as the reference solution, and the FE numerical response. The intrinsic nature of the optimized parameters, for both material damage models, was evaluated through quasi-static and dynamic modeling of a uniaxial tensile specimen (2024-T351 sheet metal plate) and an ARCAN specimen [1] in pure tension (7050 rivet).

\section{Preliminary study}

Today microstructural damage is increasingly taken into account for FE simulation of dynamic loading. A coupled mechanical-damage model, based on the evolution of the microvoid volume fraction (to describe the material porosity) and the Gurson microvoided material potential (to describe the plastic flow) was used to describe the damage process leading to ductile failure [4]. The plastic incompressibility relation determines the growth of existing microvoids, and the nucleation of new microvoids depends on the distribution of the inclusions. Tvergaard and Needleman use a special function to describe the rapid loss of stress-carrying capacity which corresponds to coalescence of the microvoids [10]. Ductile failure occurs after microvoid growth, nucleation and coalescence for a specific level of microvoid volume fraction. The Gurson model was included in PAM-CRASH ${ }^{\mathrm{TM}}$ by Lauro et al. [7] for shell and solid elements.

To use this model in PAM-CRASH ${ }^{\mathrm{TM}}$, mechanical tests had to be conducted to define the material damage parameters of the Gurson model by an inverse method.
As the damage occurs in areas of positive hydrostatic stress (i.e. tension areas), uniaxial mechanical tensile tests are the most appropriate for reproducing this stress state.

Elementary punched tension specimens (sheet metal plate) and elementary single lap riveted joint shear specimens (rivet) were chosen because of their basic geometric shape and because no special experimental set-up is required. Gauges cannot measure strains greater than 0.20 . When using typical uniaxial tensile specimens, failure starts for strains higher than this admissible range. The geometry of the punched tension specimen has the advantage of allowing plastic strains to be measured near the punched hole and placing the failure stage in the admissible strain measurement range $(0<\varepsilon<0.20)$.

Experimental techniques are more powerful. $\mathrm{Nu}-$ merous types of signals (e.g. load, displacement, strain, pressure, temperature) may be measured. To evaluate the efficiency of experimental variables, it is first of all necessary to undertake a sensitivity study.

\subsection{FE modeling details}

To introduce axial strain, one end of the specimen was restrained and nodal velocity boundary conditions were applied to the other end (Fig. 1). A velocity versus time diagram defined the nodal velocity boundary conditions. A sensitivity study was undertaken on the velocity versus time diagram in order to limit the CPU time. It showed that inertia and wave propagation effects were limited up to an impact velocity of about $10 \mathrm{~m} / \mathrm{s}$ with sinusoidal smoothing at the beginning.

The numerical variables for both specimens were: the load $F$, the local strains $\varepsilon_{S 1}$ and $\varepsilon_{S 2}$, and the radial and longitudinal local strains $\varepsilon_{R}$ and $\varepsilon_{L}$.

Strains $\varepsilon_{S 1}$ and $\varepsilon_{S 2}$ were measured far from the punched area, on the countersunk punched metal plate and on the flat punched metal plate. As these two strains remained elastic, the effects of position differences between numerical and experimental gauges did not have to be taken into account. Moreover, the strain state near the punched hole (measured by the radial and longitudinal gauges, $\varepsilon_{R}$ and $\varepsilon_{L}$ ) influenced both measurements which meant that the two metal plate behaviors (i.e. near and far from the punched hole) could be compared. The radial and longitudinal gauges measured the influence of the punched hole and the dynamic effects on the local behavior near the punched hole.

Table 1 presents the elastic, plastic and damage material parameters in terms of: 


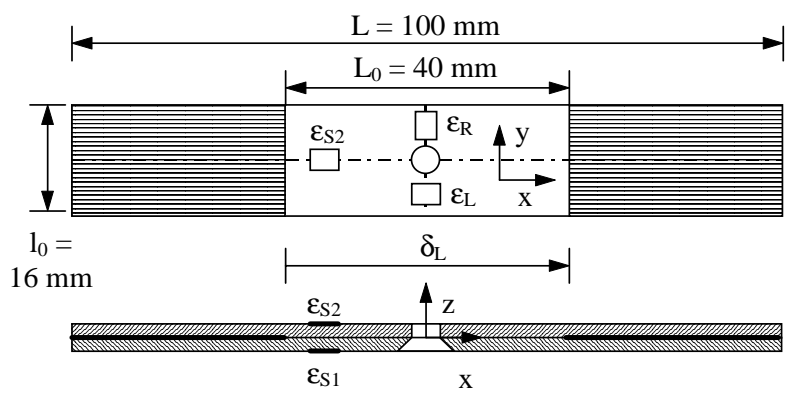

(a) Tension punched elementary specimen.

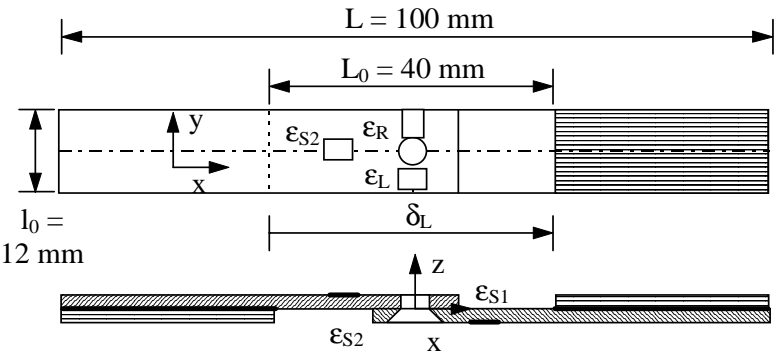

(b) Shear single lap riveted joint elementary specimen.

Fig. 1. Characterization specimens for Gurson damage model parameters identification.

Table 1

Elastic, plastic and damage materials parameters of riveted joint FE models

\begin{tabular}{|c|c|c|c|c|c|c|c|}
\hline \multirow{2}{*}{$\begin{array}{c}\text { Assembly material } \\
2024-\mathrm{T} 351 \\
\text { (sheet metal plate) }\end{array}$} & \multirow{2}{*}{$\begin{array}{c}\text { Behaviour } \\
\text { Elastic/Plastic }^{-1-} \\
\text { Tension } \\
\text { Compression }\end{array}$} & \multicolumn{6}{|c|}{ Parameters } \\
\hline & & $\begin{array}{c}\mathrm{G}^{-2-}(\mathrm{MPa}) \\
2.78210^{+4} \\
2.78210^{+4}\end{array}$ & $\begin{array}{c}\mathrm{K}^{-2-}(\mathrm{MPa}) \\
7.25510^{+4} \\
7.25510^{+4}\end{array}$ & \multicolumn{2}{|c|}{$\begin{array}{c}\mathrm{A}(\mathrm{MPa}) \\
350 \\
305.2\end{array}$} & $\begin{array}{c}\mathrm{B}(\mathrm{MPa}) \\
600 \\
305.3\end{array}$ & $\begin{array}{c}\mathrm{n} \\
0.5025 \\
0.1461\end{array}$ \\
\hline & \multirow[t]{2}{*}{ Damage $^{-3-}$} & \multicolumn{2}{|c|}{ Growth } & \multicolumn{3}{|c|}{ Nucleation } & Coalescence \\
\hline & & $\begin{array}{cc}q_{1} & q_{2} \\
1.5 & 1\end{array}$ & $\begin{array}{c}f_{I} \\
110^{-7}\end{array}$ & $\begin{array}{c}f_{N} \\
0.04\end{array}$ & $\begin{array}{l}S_{N} \\
0.1\end{array}$ & $\begin{array}{l}\varepsilon_{N} \\
0.2\end{array}$ & $\begin{array}{cc}f_{C} & f_{F} \\
0.15 & 0.25\end{array}$ \\
\hline \multirow[t]{3}{*}{ (rivet) } & $\begin{array}{c}\text { Elastic/Plastic }^{-1-} \\
\text { Compression }\end{array}$ & $\begin{array}{c}\mathrm{G}^{-2-}(\mathrm{MPa}) \\
2.78210^{+4}\end{array}$ & $\begin{array}{c}\mathrm{K}^{-2-}(\mathrm{MPa}) \\
7.25510^{+4}\end{array}$ & $\begin{array}{r}\mathrm{A}(1 \\
31\end{array}$ & $\begin{array}{l}\mathrm{Pa}) \\
5\end{array}$ & $\begin{array}{c}\mathrm{B}(\mathrm{MPa}) \\
290.5\end{array}$ & $\begin{array}{c}\mathrm{n} \\
0.2503\end{array}$ \\
\hline & Damage $^{-3-}$ & \multicolumn{2}{|c|}{ Growth } & \multicolumn{3}{|c|}{ Nucleation } & Coalescence \\
\hline & & $\begin{array}{c}q_{2} \\
1\end{array}$ & $\begin{array}{c}f_{I} \\
110^{-7}\end{array}$ & $\begin{array}{l}f_{N} \\
0.04\end{array}$ & $\begin{array}{l}S_{N} \\
0.1\end{array}$ & $\begin{array}{l}\varepsilon_{N} \\
0.2\end{array}$ & $\begin{array}{cc}f_{C} & f_{F} \\
0.15 & 0.25\end{array}$ \\
\hline
\end{tabular}

$-1-$ extract from [5].

$-2-\{G, K\}=\left\{\frac{E}{2 \cdot(1+\nu)}, \frac{E}{3 \cdot(1-2 \cdot \nu)}\right\}$.

$-3-$ extract from $[2,11,14]$ for mild steel.

- Bulk, $G$, and shear, $K$, moduli (Equation 1 )

- Power model (Equation 2) parameters $(A, B, n)$, extract from [5]

- Initial parameters of the Gurson damage model $\left(q_{1}, q_{2}, f_{I}, f_{N}, S_{N}, \varepsilon_{N}, f_{C}, f_{F}\right)$ for the two aluminum alloys (2024-T351 for the sheet metal plates, 7050 for the rivet), extracted for a mild steel from $[2,11,14]$.

$q_{1}$ and $q_{2}$ are the porous material parameters, $f_{I}$ is the initial void volume fraction, $f_{N}$ is the nucleated void volume fraction consistent with the inclusion volume fraction, $S_{N}$ is the Gaussian standard deviation, $\varepsilon_{N}$ is the nucleated effective plastic strain, and $f_{C}$ and $f_{F}$ are the critical void volume fraction at coalescence onset and at ductile failure. The meaning of the damage parameters is given in more detail in the Appendix.

$$
\begin{aligned}
& G=\frac{E}{2 \cdot(1+\nu)} \\
& K=\frac{E}{3 \cdot(1-2 \cdot \nu)}
\end{aligned}
$$

where $E$ is the Young's modulus and $\nu$ the Poisson's ratio of the material.

$$
\sigma=A+B \cdot \varepsilon_{p}^{n}
$$

where $A$ is the material yield stress, $B$ and $n$ are material hardening parameters, and $\varepsilon_{p}$ and $\sigma$ are true plastic strain and stress.

The contact between the rivet and punched hole and also between the two metal plates was controlled by a self-impacting contact interface (type 36 in PAM-CRASH ${ }^{\mathrm{TM}}$ standard) with finite friction, $k_{f}$, for Coulomb's model $\left(k_{f}=0.2\right.$, default value for a metal/metal contact).

\subsection{Finite element model simplification}

The elementary punched tension (Fig. 1(A)) and single lap riveted joint shear specimens (Fig. 1(B)) were completely modeled by:

- 5376 porous solid elements (type 26 in PAM$\mathrm{CRASH}^{\mathrm{TM}}$ standard) for the punched tension specimens 
- 6616 porous solid elements for the single lap riveted joint shear specimens.

About 3 hours and 15 hours respectively were needed on a C100-9000 HP computer to compute these two complete FE models up to occurrence of ductile failure. This CPU time is incompatible with the inverse problem optimization method (based on the comparison between the FE model and experimental data and on an iterative process). The FE models of the two specimens were simplified (i.e. geometrical symmetries and mesh refinement) to reduce the CPU time and therefore the optimization cost (50 minutes and 3 hours for a displacement of about $5 \mathrm{~mm}$ ). Simplified FE models were compared with the complete FE models whose results were used as reference. Overall, results were very similar for the two types of models.

\subsection{Sensitivity study}

The parameters were rearranged in terms of nucleation, growth and coalescence steps in order to characterize a mathematical model such as Gurson's damage model (Table 1). The interest of a measurement, $\omega_{i}$, is linked to the ease of its experimental set-up and its sensitivity to the model's parameters. In order to rank parameters by sensitivity range, the FE models were computed until occurrence of ductile failure of the specimens, with a variation of $10 \%$ on each parameter, $\underline{z}^{j}$. An instantaneous sensitivity value, $N_{S}^{i j}$, was then obtained each step of the simulation by relation (3) which determines a norm [7].

$$
\begin{aligned}
& N_{S}^{i j}= \\
& \left|\frac{\omega_{i}\left(\underline{z}^{j}+10 \%\right)-\omega_{i}\left(\underline{z}^{j}\right)}{\omega_{i}\left(\underline{z}^{j}\right)} \cdot \frac{\underline{z}^{j}}{\left(\underline{z}^{j}+10 \%\right)-\underline{z}^{j}}\right|
\end{aligned}
$$

The results of this sensitivity study showed that the FE simplifications did not change the sensitivity of the variables to the power and Gurson damage model parameters.

For the elementary punched tension specimens (2024-T351 aluminum alloy, sheet metal plate material), the sensitivity study showed that:

- $f_{I}$ and $S_{N}$ were insensitive parameters

- $A, B$ and $n$ were sensitive parameters between the beginning of plasticity and the coalescence step

- $q_{1}, q_{2}, f_{N}$ and $\varepsilon_{N}$ were sensitive parameters between necking and the coalescence step

- $f_{C}$ and $f_{F}$ were sensitive parameters between the coalescence step and failure of the specimen.
For the single lap riveted joint shear specimens (7050 aluminum alloy, rivet material), the sensitivity study did not show a sensitivity range of the parameters. In effect, for all variables, reduced sensitivity was observed during the elastic and plastic steps (strong participation of the metal plates in the observed response) and significant sensitivity during the rivet failure step (total participation of the rivet). For the rivet damage parameters it would appear necessary to perform global identification of the parameters.

\section{Experiment}

The aim in this experimental study was to:

- Determine a set of experimental variables in order to identify the damage behavior of both aluminum alloys by the inverse method

- Study the influence of strain rate on the behavior of a punched sheet metal plate specimen and a riveted joint specimen.

Experiments were carried out on elementary specimens, Fig. 1:

- Two 2024-T351 aluminum alloy punched plates: thickness: $t=1.6 \mathrm{~mm}$

- One 7050 aluminum alloy countersunk rivet (for the single lap riveted joint shear specimen): shank diameter $\phi=4 \mathrm{~mm}$, initial length $L_{R}=8 \mathrm{~mm}$.

A minimum margin between the rivet and the metal plate edge, $a$, (edge margin) or between two rivets, $p$, (pitch) must be defined to design a riveted joint. These values are defined from calculation rules [3] or tables [12]. In our specimens, the edge margin obtained was $8 \mathrm{~mm}$ for the punched tension specimen and $6 \mathrm{~mm}$ for the single lap riveted joint shear specimen.

\subsection{Experimental set-up}

The specimens were prepared by Dassault Aviation. Holes were drilled and punched by standard industrial methods. The dimensions of the flat and countersunk punched holes were based on Dassault Aviation's manufacturing standards for a $4 \mathrm{~mm}$ diameter countersunk rivet. The punched plates were cut at ONERALille by electron discharge machining (EDM). The rivet is called "permanent" because the installation time is much longer than for the so-called "soaking rivet". Such permanent rivets are increasingly used to assemble airframes because of their installation flexibility. 


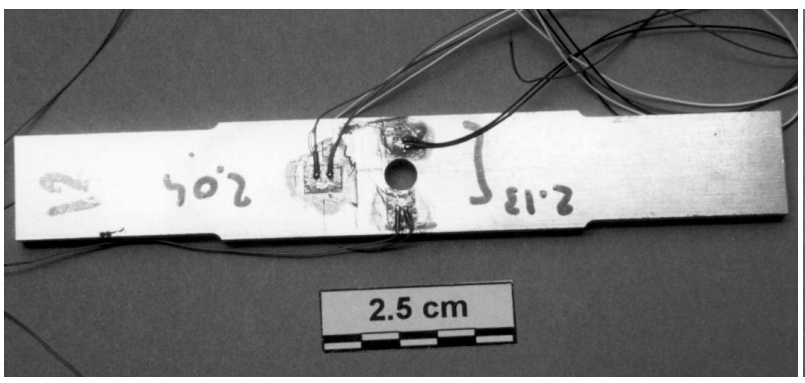

(a) Tension punched elementary specimen.

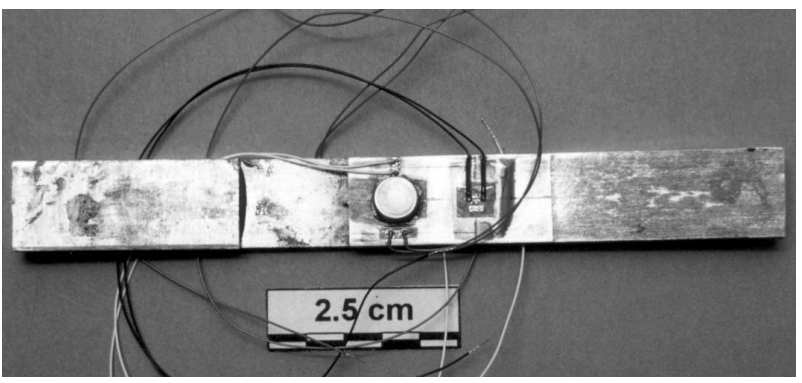

(b) Shear single lap riveted joint elementary specimen.

Fig. 2. Test specimens.

The single lap shear specimens were riveted according to standardized geometric criteria for the strain level and the volume of the driven rivet head [13].

Elementary punched tension and single lap riveted joint shear specimens were prepared in order to measure (Fig. 1):

- Specimen loading (Kistler 9077 piezoelectric load cell)

- Local strains $\varepsilon_{S 1}$ and $\varepsilon_{S 2}$ (Vishay ref. EA06015EH120 microgauges)

- Local strains $\varepsilon_{R}$ and $\varepsilon_{L}$ (Vishay ref. EP08015CK120 microgauges for the elementary punched tension specimens; Vishay ref. EA06015EH120 microgauges for the shear single lap riveted joint elementary specimens)

- Displacement $\delta_{L}$ (Keyence laser displacement transducer).

For the single lap riveted joint shear specimen, the sensitivity study showed that rivet instrumentation would yield higher quality variables for identifying the Gurson damage parameters. Unfortunately this type of instrumentation cannot be undertaken without modifying or damaging the rivet.

The specimen's instrumentation is shown in more detail in Fig. 2. The specimens were loaded with quasi-static and dynamic imposed velocity, $V_{\mathrm{imp}}=$ (3 $10^{-5} \mathrm{~m} . \mathrm{s}^{-1}, 0.2 \mathrm{~m} . \mathrm{s}^{-1}, 1 \mathrm{~m} . \mathrm{s}^{-1}, 5 \mathrm{~m} . \mathrm{s}^{-1}$ ). The tests were performed on the ONERA-Lille Schenck displacement-controlled hydraulic actuator (maximum load and velocity: $7010^{3} \mathrm{~N}$ and $10 \mathrm{~m} \cdot \mathrm{s}^{-1}$ ).

\subsection{Results for 2024-T351 aluminum alloy (sheet metal plate material)}

The mean results of quasi-static and dynamic tension tests are summarized in Table 2 and Table 3 . The results are given in terms of:
Table 2

Global results of the quasi-static and dynamic tension tests

\begin{tabular}{|c|c|c|c|c|c|}
\hline \multirow{2}{*}{$\begin{array}{l}V_{\mathrm{imp}} \\
(\mathrm{m} / \mathrm{s})\end{array}$} & \multirow{2}{*}{$\begin{array}{l}F_{\max } \\
(\mathrm{kN})\end{array}$} & \multirow{2}{*}{$\begin{array}{l}F_{\mathrm{u}} \\
(\mathrm{kN})\end{array}$} & \multirow{2}{*}{$\begin{array}{l}A_{\text {res }} \\
(\mathrm{mm})\end{array}$} & \multicolumn{2}{|c|}{ Failure pattern } \\
\hline & & & & plane $^{-4-}$ & thickness \\
\hline $310^{-5}$ & 16 & 15 & 1.28 & 1 & $\pm 45^{\circ}$ \\
\hline 0.2 & 16 & 15.1 & 1.33 & $1-2$ & $\pm 45^{\circ}$ \\
\hline 1 & 16.4 & 15.2 & 1.3 & $3-4$ & $\pm 45^{\circ} / 0^{\circ}$ \\
\hline 5 & 16.8 & 15.3 & 1.3 & $3-4$ & $\pm 45^{\circ} / 0^{\circ}$ \\
\hline \multicolumn{6}{|c|}{$-4-$ According to the specifications reported in Fig. 5.} \\
\hline \multicolumn{6}{|c|}{$\begin{array}{l}-F_{\max } \text { and } F_{\mathrm{u}} \text {, the maximum load and the ultimate } \\
\text { load }\end{array}$} \\
\hline \multicolumn{6}{|c|}{$\begin{array}{l}-\varepsilon_{\max } \text { and } \varepsilon_{u} \text {, the strain states corresponding to the } \\
\text { maximum load and the ultimate load } \\
-A_{\text {res }} \text {, the final elongation measured after the tests } \\
\text { by reconstruction of the specimen. }\end{array}$} \\
\hline
\end{tabular}

Three ranges (elastic, plastic and ultimate) were determined according to the loading (Fig. 3). Strain rates $\left(\dot{\varepsilon}_{e}, \dot{\varepsilon}_{p}\right.$ and $\dot{\varepsilon}_{u}$ ) are given according to these ranges (Table 4 ). Figure 4 presents the experimental patterns and Fig. 5 their schematic.

Strain rates were found not to affect the maximum load $F_{\max }$, the ultimate load $F_{u}$ and the final elongation of the specimen $A_{\text {res }}$. The differences observed between the quasi-static and dynamic velocities were the result of a natural vibration frequency of the experimental set-up. The mean maximum and ultimate loads were about $1610^{3} \mathrm{~N}$ and $1510^{3} \mathrm{~N}$. The mean final elongation was about $1.3 \mathrm{~mm}$.

Similarly, the strain rate did not affect the strain state observed at the maximum load $F_{\text {max }}$. For all tests (quasi-static and dynamic), $\varepsilon_{S 2}$ was always higher than $\varepsilon_{S 1}$. This result indicated that the countersunk punched metal plate was more deformed near the punched hole than the flat punched plate. At maximum load, the mean strain state was about: $\varepsilon_{S 1}=0.2110^{-2}$ (countersunk punched plate), $\varepsilon_{S 2}=0.3310^{-2}$ (flat punched plate), $\varepsilon_{R}=-1.510^{-2}, \varepsilon_{L}=5.010^{-2}$.

At ultimate load, the strain state measured by $\varepsilon_{S 1}, \varepsilon_{S 2}, \varepsilon_{R}, \varepsilon_{L}$ remained more or less unchanged 


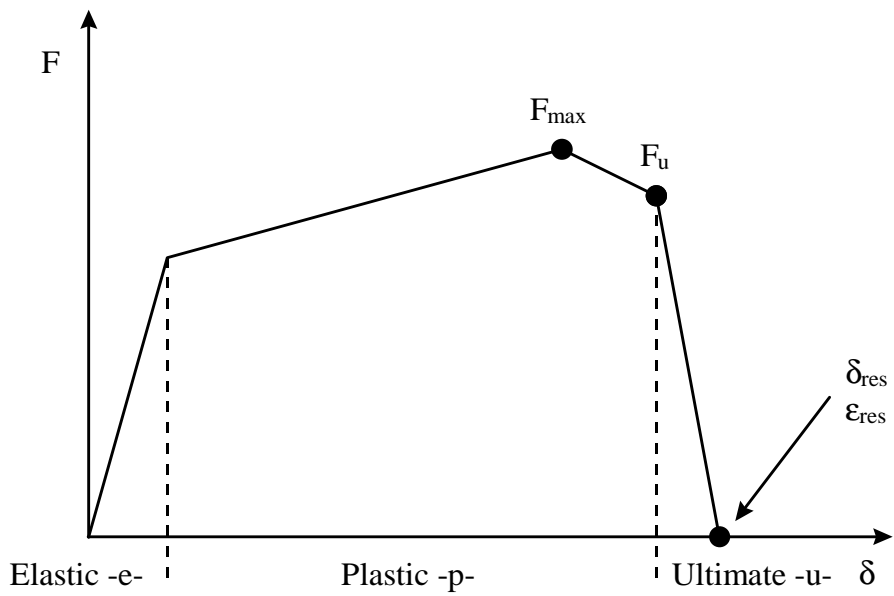

Fig. 3. Behavior areas.

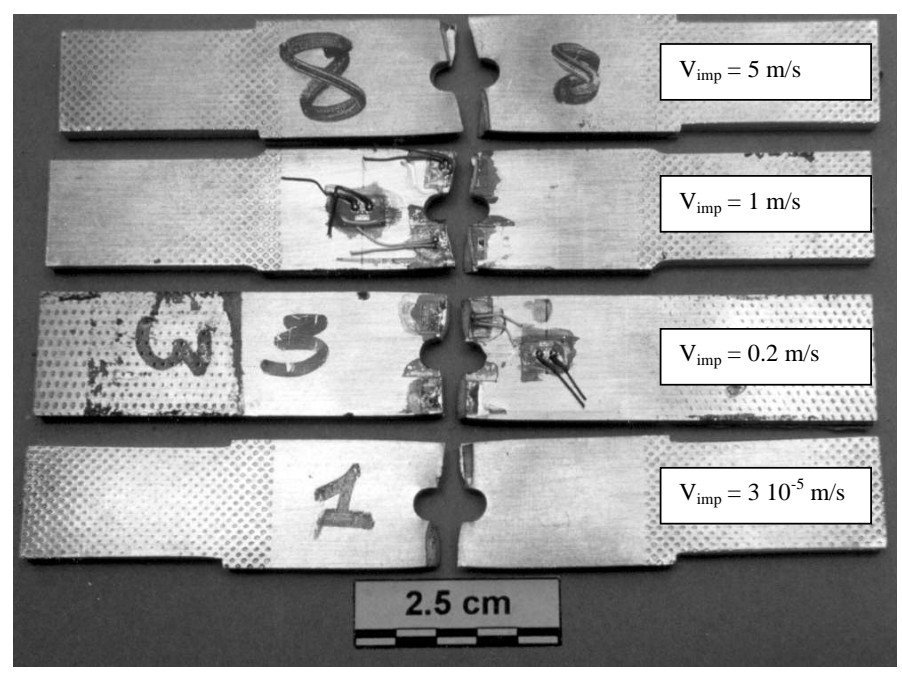

Fig. 4. Experimental patterns of punched tension specimens.

when the imposed velocity increased. The strain measured on the countersunk punched metal plate $\left(\varepsilon_{S 1}\right)$ was zero (broken). The mean strain measured on the flat punched metal plate $\left(\varepsilon_{S 2}\right)$ was about $0.3610^{-2}$ (unbroken). This result shows that flat punching is more favorable than countersunk punching (smaller cross section with countersunk punching). The strain levels measured by the radial and longitudinal gauges were about $-210^{-2}$ and $710^{-2}$.

\subsection{Synthesis for 2024-T351 aluminum alloy (sheet metal plate material)}

The quasi-static and dynamic tests did not evidence any strain rate effects on the experimental variables, although some plastic and ultimate strain rates from
500 to $7000 \mathrm{~s}^{-1}$ were measured (in the highly stressed area near the punched hole).

Nevertheless, post-test observation of the specimen profiles seems to depend on the imposed velocity. The failure is mainly straight in the plane of the specimen and at $\pm 45^{\circ}$ across the metal plate thickness for the quasi-static tests (pattern 1, Fig. 5). The imposed velocity increase moves the failure orientation to the plane of the specimen. The failure is straighter in the metal plate thickness for the dynamic tests (patterns 3 and 4, Fig. 5). An intermediate state observed for the mean dynamic tests $\left(0.2 \mathrm{~m} . \mathrm{s}^{-1}\right)$ moves the straight failure in the metal plate plane on both sides of the transverse axis of the punched hole (pattern 2, Fig. 5).

The strain rate measured in each range of behavior (elastic, plastic and ultimate) and for each gauge has 
Table 3

Local results of the quasi-static and dynamic tension tests

\begin{tabular}{|c|c|c|c|c|c|c|c|c|}
\hline \multirow{2}{*}{$\begin{array}{l}V_{\mathrm{imp}} \\
(\mathrm{m} / \mathrm{s})\end{array}$} & \multicolumn{4}{|c|}{$\varepsilon_{\max }$} & \multicolumn{3}{|c|}{$\varepsilon_{u}$} & \multirow[b]{2}{*}{$\begin{array}{l}\varepsilon_{L} \\
(\%)\end{array}$} \\
\hline & $\begin{array}{l}\varepsilon_{S 1} \\
(\%)\end{array}$ & $\begin{array}{l}\varepsilon_{S 2} \\
(\%)\end{array}$ & $\begin{array}{l}\varepsilon_{R} \\
(\%)\end{array}$ & $\begin{array}{l}\varepsilon_{L} \\
(\%)\end{array}$ & $\begin{array}{l}\varepsilon_{S 1} \\
(\%)\end{array}$ & $\begin{array}{l}\varepsilon_{S 2} \\
(\%)\end{array}$ & $\begin{array}{l}\varepsilon_{R} \\
(\%)\end{array}$ & \\
\hline $310^{-5}$ & 0.22 & 0.31 & -1.7 & 4.65 & 0 & 0.37 & -1.85 & 6.9 \\
\hline 0.2 & 0.22 & 0.31 & -1.4 & 5.25 & 0 & 0.31 & -2.1 & 7.28 \\
\hline 1 & 0.22 & 0.32 & -1.5 & 5.00 & 0 & 0.34 & -2.2 & 7.0 \\
\hline 5 & 0.2 & 0.37 & -1.6 & 5.00 & 0 & 0.40 & -2.5 & 7.3 \\
\hline
\end{tabular}

Table 4

Local strain rates of the quasi-static and dynamic tension tests

\begin{tabular}{|c|c|c|c|c|c|c|c|c|c|c|c|c|}
\hline \multirow{2}{*}{$\begin{array}{l}V_{\mathrm{imp}} \\
(\mathrm{m} / \mathrm{s})\end{array}$} & \multicolumn{4}{|c|}{$a-$ in the elastic area } & \multicolumn{4}{|c|}{$b-$ in the plastic area } & \multicolumn{4}{|c|}{$b-$ in the ultimate area } \\
\hline & $\begin{array}{c}\dot{\varepsilon}_{S 1} \\
\left(\mathrm{~s}^{-1}\right)\end{array}$ & $\begin{array}{c}\dot{\varepsilon}_{S 2} \\
\left(s^{-1}\right)\end{array}$ & $\begin{array}{c}\dot{\varepsilon}_{R} \\
\left(\mathrm{~s}^{-1}\right)\end{array}$ & $\begin{array}{c}\dot{\varepsilon}_{L} \\
\left(s^{-1}\right)\end{array}$ & $\begin{array}{c}\dot{\varepsilon}_{S 1} \\
\left(\mathrm{~s}^{-1}\right)\end{array}$ & $\begin{array}{c}\dot{\varepsilon}_{S 2} \\
\left(s^{-1}\right)\end{array}$ & $\begin{array}{c}\dot{\varepsilon}_{R} \\
\left(s^{-1}\right)\end{array}$ & $\begin{array}{c}\dot{\varepsilon}_{L} \\
\left(\mathrm{~s}^{-1}\right)\end{array}$ & $\begin{array}{c}\dot{\varepsilon}_{S 1} \\
\left(s^{-1}\right)\end{array}$ & $\begin{array}{c}\dot{\varepsilon}_{S 2} \\
\left(s^{-1}\right) \\
\end{array}$ & $\begin{array}{c}\dot{\varepsilon}_{R} \\
\left(s^{-1}\right)\end{array}$ & $\begin{array}{c}\dot{\varepsilon}_{L} \\
\left(\mathrm{~s}^{-1}\right)\end{array}$ \\
\hline $310^{-5}$ & $110^{-4}$ & $110^{-4}$ & $-410^{-5}$ & $1.510^{-4}$ & $210^{-5}$ & $310^{-5}$ & $-110^{-3}$ & $210^{-3}$ & $-110^{-4}$ & $-110^{-4}$ & $-7.510^{-3}$ & $110^{-2}$ \\
\hline 0.2 & 2 & 2.2 & -1 & 3 & 0.14 & 0.14 & -6 & 13 & -5 & -11 & -375 & 400 \\
\hline 1 & 7.5 & 10 & -2.3 & 7.2 & 0.7 & 0.8 & -26 & 60 & -20 & -40 & -1250 & 1500 \\
\hline 5 & 25 & 37 & -15 & 47 & 4 & 6 & -220 & 500 & -98 & -300 & -6000 & 7000 \\
\hline
\end{tabular}

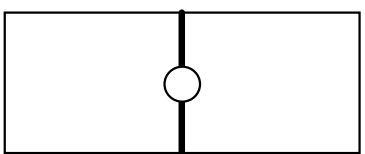

1

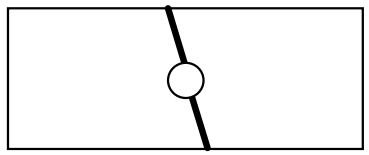

3

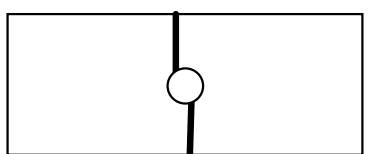

2

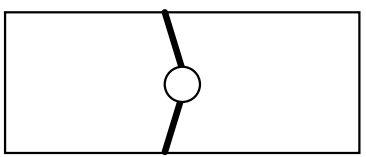

4
Fig. 5. Pattern schematic of punched tension specimens.

some influence on the local behavior:

- For the elastic step, the difference in elastic strain rate observed between the gauges $\varepsilon_{S}$ and $\varepsilon_{L}$ is due to the smaller cross section (punching)

- For the plastic step, the plastic strain location is observed for the reduced cross section. This location leads to increased plastic strain rates in the area near the punched hole $\left(\varepsilon_{L}\right.$ and $\left.\varepsilon_{R}\right)$ and to decreased elastic strain rates for gauges $\varepsilon_{S 1}$ and $\varepsilon_{S 2}$,

- For the ultimate step, gauges $\varepsilon_{S 1}$ and $\varepsilon_{S 2}$ show specimen relaxation (strain rates are negative). At the same time, the strain rates measured by gauges $\varepsilon_{R}$ and $\varepsilon_{L}$ suddenly increase. Necking (coalescence characteristic) and the plastic strain location finally lead to specimen failure on both sides of the punched hole.

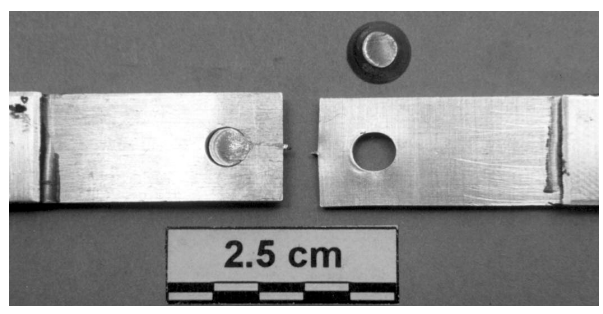

Fig. 6. Shear test failure mode.

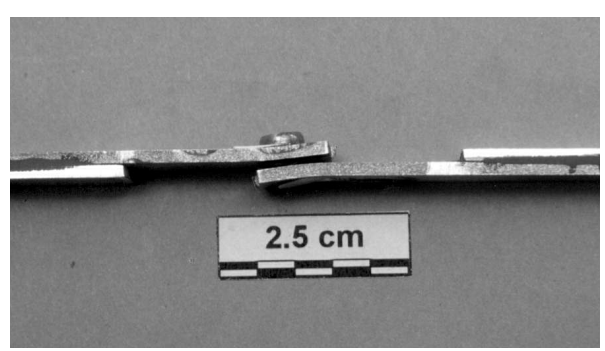

Fig. 7. Metal plate deflection.

\subsection{Results for 7050 aluminum alloy (rivet material)}

The results of quasi-static and dynamic single lap shear tests are summarized in Table 5 and Table 6 in the same way. Strain rates are given for each gauge according to the same elastic, plastic and ultimate steps (Table 7).

The strain rate does not affect the maximum and ultimate loads $F_{\max }$ and $F_{\mathrm{u}}$ or the final elongation of the specimen $A_{\text {res }}$. The mean maximum and ultimate loads were about $3.2110^{3} \mathrm{~N}$ and $310^{3} \mathrm{~N}$. The mean final elongation of the specimen is about $1.55 \mathrm{~mm}$. The failure mode of the specimen remained unchanged 
Table 5

Global results of the quasi-static and dynamic shear tests

\begin{tabular}{ccccc}
\hline$V_{\mathrm{imp}}(\mathrm{m} / \mathrm{s})$ & $F_{\max }(\mathrm{kN})$ & $F_{\mathrm{u}}(\mathrm{kN})$ & $A_{\text {res }}(\mathrm{mm})$ & Rivet failure $^{-5-}$ \\
\hline $310^{-5}$ & 3.29 & 3.13 & 1.55 & SRCH \\
0.2 & 3.21 & 3.12 & 1.55 & SRCH \\
1 & 3.2 & 2.96 & 1.55 & SRCH \\
5 & 3.21 & 2.96 & 1.55 & SRCH \\
\hline
\end{tabular}

$-5-$ SRCH: Shear of Rivet Countersunk Head.

Table 6

Local results of the quasi-static and dynamic shear tests

\begin{tabular}{|c|c|c|c|c|c|c|c|c|}
\hline \multirow{2}{*}{$\begin{array}{l}V_{\mathrm{imp}} \\
(\mathrm{m} / \mathrm{s})\end{array}$} & \multicolumn{4}{|c|}{$\varepsilon_{\max }$} & \multicolumn{3}{|c|}{$\varepsilon_{u}$} & \multirow[b]{2}{*}{$\begin{array}{l}\varepsilon_{L} \\
(\%)\end{array}$} \\
\hline & $\begin{array}{l}\varepsilon_{S 1} \\
(\%)\end{array}$ & $\begin{array}{l}\varepsilon_{S 2} \\
(\%)\end{array}$ & $\begin{array}{l}\varepsilon_{R} \\
(\%)\end{array}$ & $\begin{array}{l}\varepsilon_{L} \\
(\%)\end{array}$ & $\begin{array}{l}\varepsilon_{S 1} \\
(\%)\end{array}$ & $\begin{array}{l}\varepsilon_{S 2} \\
(\%)\end{array}$ & $\begin{array}{l}\varepsilon_{R} \\
(\%)\end{array}$ & \\
\hline $310^{-5}$ & 0.09 & 0.13 & 0.12 & -0.52 & 0.09 & 0.13 & 0.12 & -0.52 \\
\hline 0.2 & 0.24 & 0.23 & 0.14 & -0.52 & 0.24 & 0.23 & 0.11 & -0.52 \\
\hline 1 & 0.20 & 0.20 & 0.11 & -0.48 & 0.20 & 0.20 & 0.11 & -0.48 \\
\hline 5 & 0.20 & 0.20 & 0.13 & -0.48 & 0.20 & 0.20 & 0.13 & -0.48 \\
\hline
\end{tabular}

Table 7

Local strain rates of the quasi-static and dynamic shear tests

\begin{tabular}{|c|c|c|c|c|c|c|c|c|c|c|c|c|}
\hline \multirow{2}{*}{$\begin{array}{l}V_{\mathrm{imp}} \\
(\mathrm{m} / \mathrm{s})\end{array}$} & \multicolumn{4}{|c|}{$a-$ in the elastic area } & \multicolumn{4}{|c|}{$b-$ in the plastic area } & \multicolumn{4}{|c|}{$b-$ in the ultimate area } \\
\hline & $\begin{array}{c}\dot{\varepsilon}_{S 1} \\
\left(\mathrm{~s}^{-1}\right)\end{array}$ & $\begin{array}{c}\dot{\varepsilon}_{S 2} \\
\left(\mathrm{~s}^{-1}\right)\end{array}$ & $\begin{array}{c}\dot{\varepsilon}_{R} \\
\left(\mathrm{~s}^{-1}\right)\end{array}$ & $\begin{array}{c}\dot{\varepsilon}_{L} \\
\left(\mathrm{~s}^{-1}\right)\end{array}$ & $\begin{array}{c}\dot{\varepsilon}_{S 1} \\
\left(\mathrm{~s}^{-1}\right)\end{array}$ & $\begin{array}{c}\dot{\varepsilon}_{S 2} \\
\left(\mathrm{~s}^{-1}\right)\end{array}$ & $\begin{array}{c}\dot{\varepsilon}_{R} \\
\left(\mathrm{~s}^{-1}\right)\end{array}$ & $\begin{array}{c}\dot{\varepsilon}_{L} \\
\left(\mathrm{~s}^{-1}\right)\end{array}$ & $\begin{array}{c}\dot{\varepsilon}_{S 1} \\
\left(\mathrm{~s}^{-1}\right)\end{array}$ & $\begin{array}{c}\dot{\varepsilon}_{S 2} \\
\left(\mathrm{~s}^{-1}\right)\end{array}$ & $\begin{array}{c}\dot{\varepsilon}_{R} \\
\left(\mathrm{~s}^{-1}\right)\end{array}$ & $\begin{array}{c}\dot{\varepsilon}_{L} \\
\left(\mathrm{~s}^{-1}\right)\end{array}$ \\
\hline $310^{-5}$ & $1.310^{-4}$ & $110^{-4}$ & $510^{-5}$ & $-1.310^{-4}$ & $410^{-5}$ & $710^{-5}$ & $410^{-5}$ & $-1.310^{-4}$ & $-110^{-3}$ & $-110^{-3}$ & $-410^{-4}$ & $110^{-3}$ \\
\hline 0.2 & 1 & 1 & 0.1 & -1 & 0.4 & 0.1 & 0.16 & -0.7 & -2 & -2 & -0.52 & 2.1 \\
\hline 1 & 2.7 & 2.5 & 1.6 & -3 & 2 & 2.5 & 1.6 & -5 & -26 & -24 & -5.2 & 28 \\
\hline 5 & 7 & 4.5 & 5 & -10 & 7 & 4.5 & 5 & -10 & -35 & -32 & -14.8 & 30 \\
\hline
\end{tabular}

according to strain rate: the countersunk rivet head was torn (Fig. 6). For the strain gauge positions, plastic strains were measured although the metal plates were plastically bent (Fig. 7).

For the maximum or ultimate load, the strain state measured by the radial and longitudinal gauges was not found to be affected by the strain rate. At maximum load, radial and longitudinal strain levels of about 0.12 $10^{-} 2$ and $-0.510^{-2}$ were observed. The radial and longitudinal gauges measured the metal plate deflection during the shear test $\left(\varepsilon_{L}<0\right.$ and $\left.\varepsilon_{R}>0\right)$. No significant change of the strain rate between the elastic, plastic or ultimate steps was observed (Table 7).

\subsection{Synthesis for 7050 aluminum alloy (rivet material)}

Quasi-static and dynamic single lap shear tests did not show any influence of strain rates on the global or local variables or on the failure mode of the specimen. The tests led to a countersunk rivet head shearing failure mode, not a pull-out failure mode. The results can therefore be used to identify the Gurson damage parameters of the rivet material by an inverse method. Rivet damage is only partially measured by the vari- ables (global load and local metal plate strains) during the experimental stage. Optimization is then carried out with these variables.

As shown by the sensitivity study, $90 \%$ of the response sensitivity comes from:

- The 2024-T351 aluminum alloy metal plate between the elastic and plastic steps of the test

- The 7050 aluminum alloy rivet for the failure step.

It is now clear that it will be necessary to globally optimize the Gurson damage parameters of the rivet.

\section{Identification of damage parameters (Gurson model)}

The inverse problem optimization method consists in minimizing the difference between experimental variables and those from FE models. The simplified FE models were chosen for the inverse problem optimization method for obvious reasons of CPU time and optimization costs. Only results related to the load versus displacement diagrams are presented in this paper. The internally developed OPTB2L program [6] was used to optimize the parameters of Gurson model. This pro- 


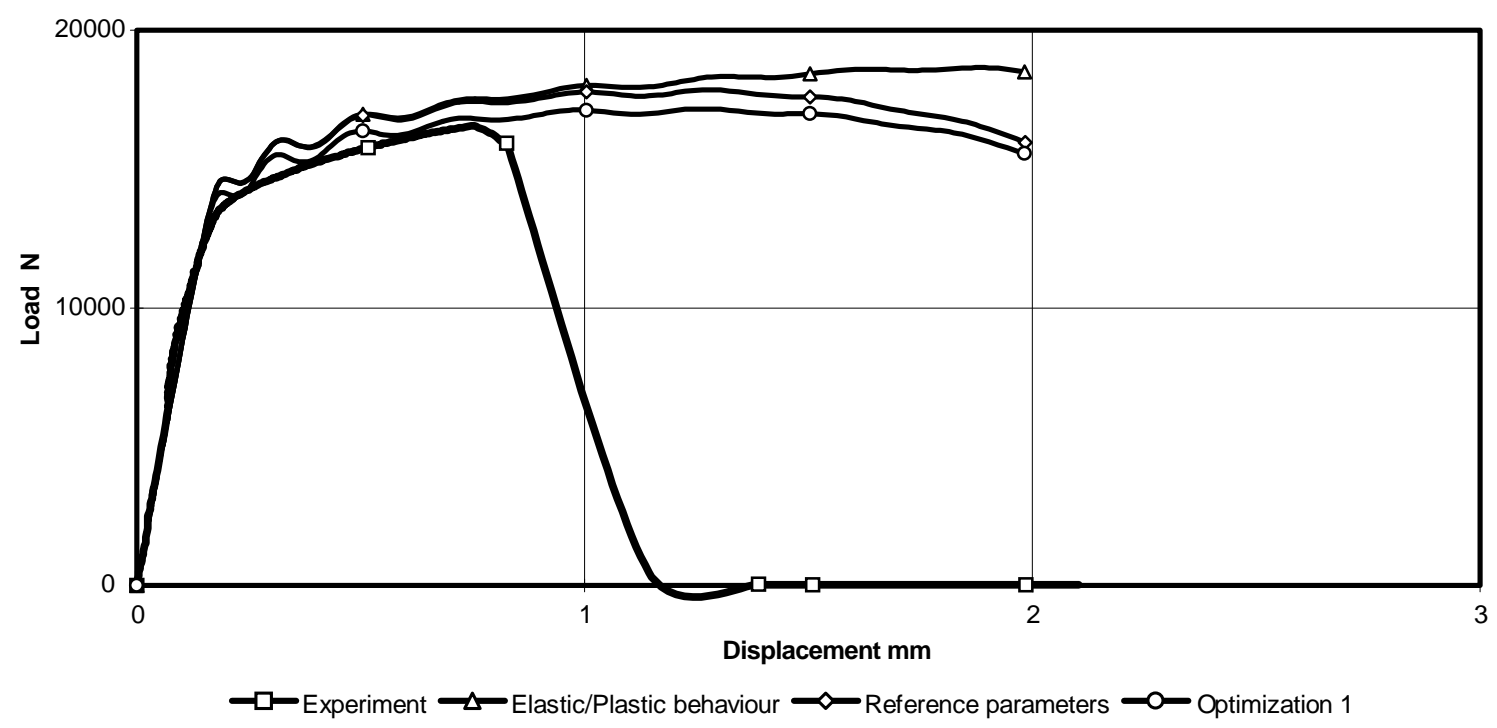

Fig. 8. Comparison of experimental and numerical results - First optimization - (Punched tension specimens - 2024-T351 aluminium alloy).

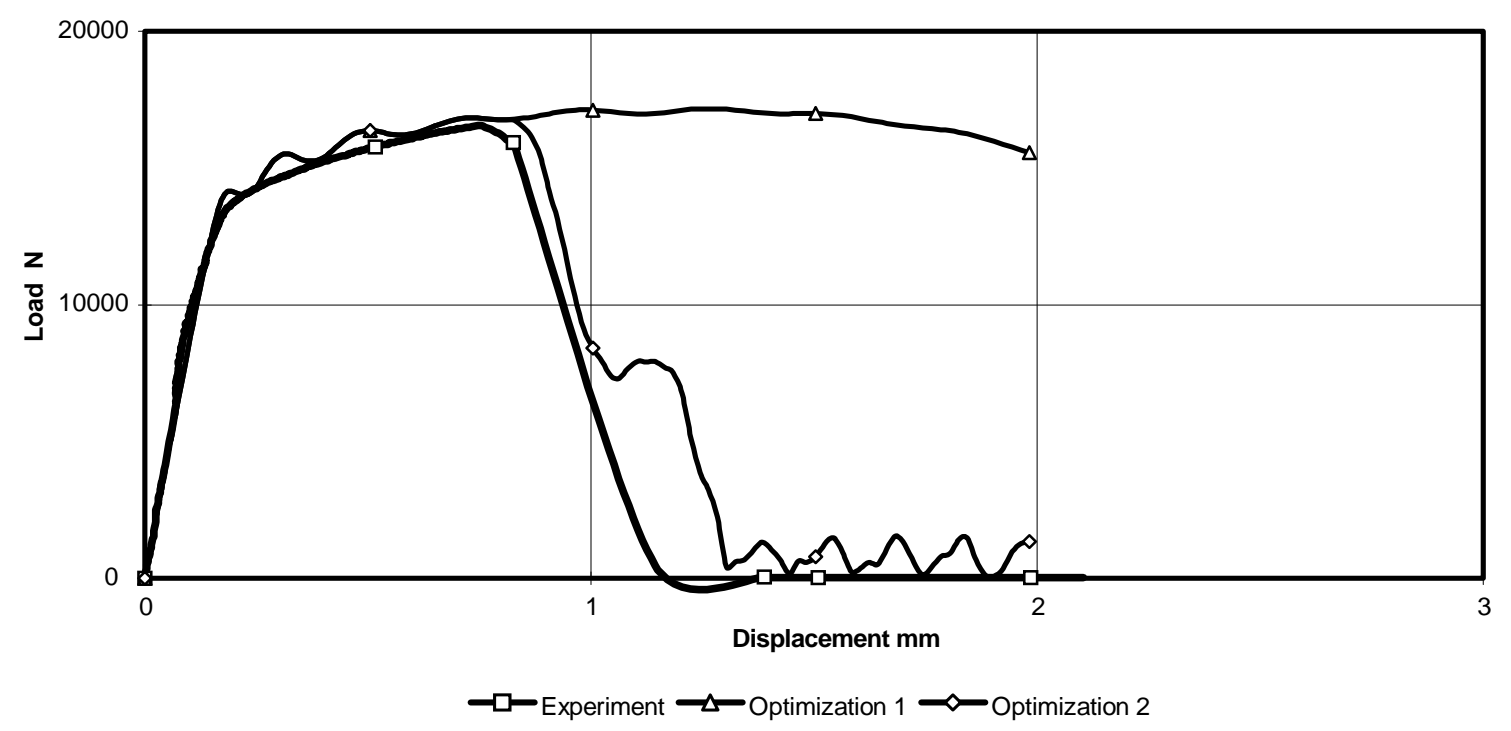

Fig. 9. Comparison of experimental and numerical results - Second optimization - (Punched tension specimens - 2024-T351 aluminium alloy).

gram is based on the conjugate gradient method and on the Davidon-Fletcher-Powell and Broyden-FletcherGoldfarb-Shanno algorithms (DFP and BFGS) [9]. The $f(\underline{z})$ criterion (or cost function) is defined by the least error squares method (Equation 4).

$$
f(\underline{z})=\sum_{i=1}^{N_{p}} \frac{\left[\omega_{i}^{\text {num }}(\underline{z})-\omega_{i}^{\exp }\right]^{2}}{\left[\omega_{i}^{\exp }\right]^{2}}
$$

where $N_{p}$ represents the number of experimental points, $z$ is the parameter vector to be identified, $\omega_{i}^{\exp }$ and $\omega_{i}^{\text {num }}$ are an experimental and a numerical measurement.

The following parameter vector initializes the optimization process:

$$
\begin{aligned}
\underline{z}^{0} & =\left(q_{1}, q_{2}, f_{I}, f_{N}, S_{N}, \varepsilon_{N}, f_{C}, f_{F}\right) \\
& =\left(1.5,1,1.10^{-7}, 0.04,0.1,0.2,0.15,0.25\right)
\end{aligned}
$$

\subsection{4-T351 aluminum alloy (sheet metal plates)}

The sensitivity study evidenced the sensitivity of several damage parameters: $f_{N}$ and $\varepsilon_{N}$ for the nucleation 


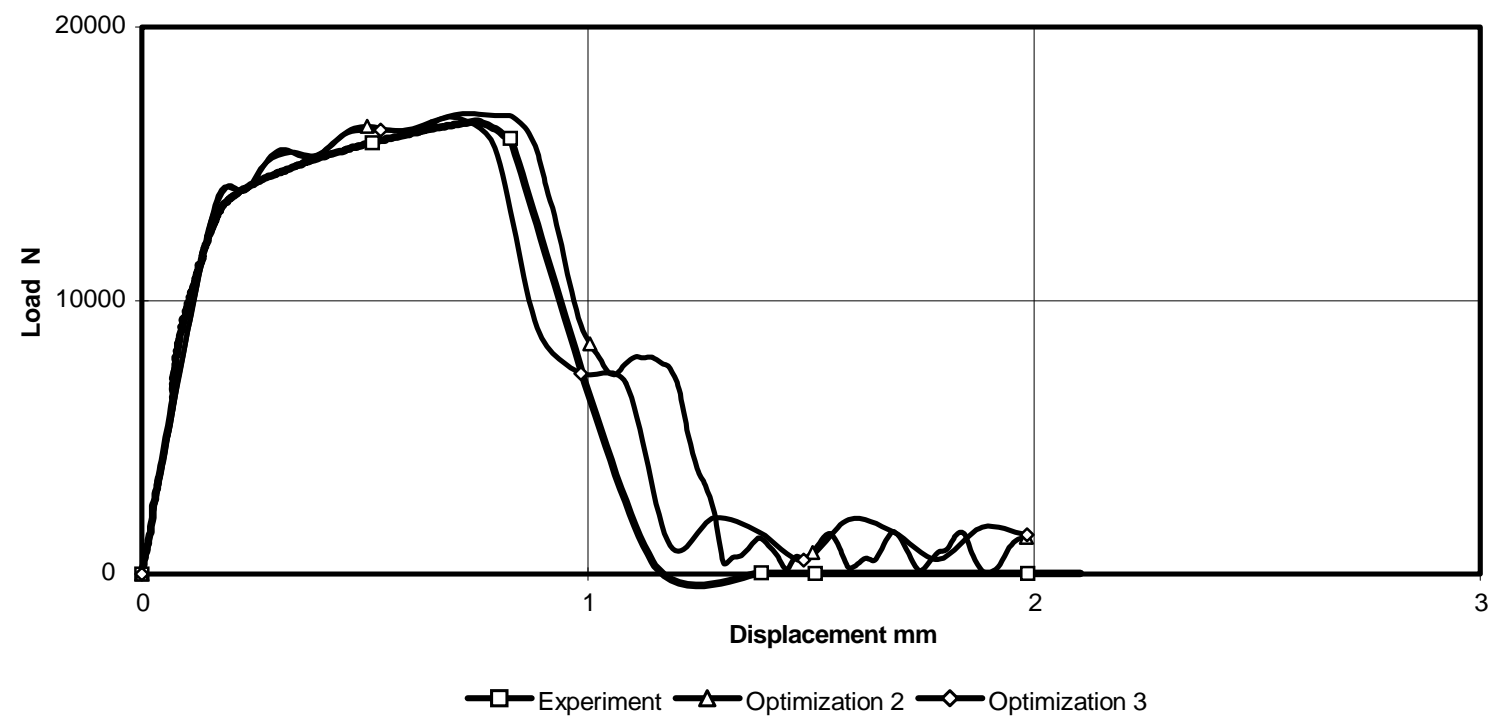

Fig. 10. Comparison of experimental and numerical results - Third optimization - (Punched tension specimens - 2024-T351 aluminium alloy).

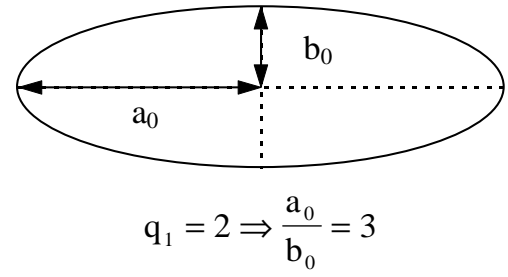

Fig. 11. Identified elliptic microvoid shape.

step, $q_{1}$ and $q_{2}$ for the growth step, $f_{C}$ and $f_{F}$ for the failure step. Optimization was then performed in three steps:

- Nucleation parameters

- Failure parameters

- Growth parameters.

For the first optimization (nucleation parameters), the FE models and the experimental data were compared from the beginning of the test until the beginning of necking (range where the two parameters are sensitive). The parameter vector $\underline{z}^{1}=\left(f_{N}, \varepsilon_{N}\right)=$ $(0.04,0.2)$ initialized the optimization process. The first optimization solution was $\underline{z}_{1}=(0.04,0.1)$. Figure 8 shows that the behavior is correctly described until there is a displacement on the order of $0.8 \mathrm{~mm}$. Optimization of only these two parameters is not sufficient to be able to predict or approximate the displacement at failure.

Once the nucleation step is over, ductile failure (coalescence) of the material is retarded by the intermediate growth step. This growth step moreover has a key influence on the necking step development (negative hardening), but not on the failure step. Optimization of the growth parameters will only allow a minor improvement. The results of the first optimization showed that it was now logical to identify the failure parameters. For this reason, the coalescence parameter $f_{C}$ was set to $f_{N}\left(f_{C}=f_{N}\right)$ and the ultimate microvoid volume fraction $f_{F}$ was such that $f_{F} \cdot 0.9 \geqslant f_{C}$. Setting $f_{N}$ to a value greater than $f_{C}$ is meaningless [2,11,14]. The minimum value of $f_{F}\left(f_{F}=f_{C} / 0.9\right)$ is advised to avoid numerical instabilities. As failure occurs rapidly, this minimum value of $f_{F}$ is a good starting point for the second optimization step. The second optimization proposes $f_{F}=0.05$ as new $f_{F}$ value. The results obtained after the optimization of $f_{F}$ showed that it would be necessary to consider $f_{C}<f_{N}$ to cause the failure to occur earlier (Fig. 9). As this is meaningless, it is preferable to identify the parameters up to now as a part of the optimization process: $q_{1}$ and $q_{2}$. The last optimization $\left(q_{1}\right.$ or $\left.q_{2}\right)$ is undertaken to speed up the nucleation and growth steps. The critical microvoid volume fraction at the onset of coalescence, $f_{C}$ (identified to the maximum nucleated volume fraction $f_{N}$ ), is therefore reached more quickly.

The initial values of $q_{1}$ and $q_{2}$ propose a spherical microvoid shape. A modification of $q_{1}$ or $q_{2}$ modifies the Gurson microvoided material potential. It also introduces damage orientation by an elliptic microvoid shape (roll sheet anisotropy). The elliptic microvoid shape is described by relations $(5,6) . q_{1}^{*}$ is equal to 1.5 (i.e. spherical shape) and $m_{0}$ represents the initial 
radial deviation of the elliptic microvoid shape. $a_{0}$ is the length of the ellipse semiaxis parallel to the main strain direction. $b_{0}$ is the ellipse semiaxis orthogonal to the same direction.

$$
\begin{aligned}
& q_{1}=q_{1}^{*}+m_{0} \\
& m_{0}=\frac{a_{0}-b_{0}}{a_{0}+b_{0}}
\end{aligned}
$$

The identification of $q_{1}$ by an inverse method leads to $q_{1}=2$. This last result correctly describes the entire experimental diagram (Fig. 10). The elliptic microvoid shape described by $q_{1}=2$ corresponds to an $a_{0} / b_{0}$ aspect ratio equal to 3 (Fig. 11).

\subsection{0 aluminum alloy (rivet)}

An elastic-plastic model (without damage) of the shear experiment leads to a pull-out rivet failure mode. Figure 12 shows that the pull-out and shear rivet failure modes are dissimilar for this kind of specimen (from an energy dissipation point of view). With the reference damage parameters (mild steel), the failure mode is similar to the elastic-plastic one and so is not satisfactory (no material failure).

A first optimization was carried out to identify the failure parameters of the rivet material $\left(f_{C}\right.$ and $\left.f_{F}\right)$. This optimization gave satisfactory results in terms of a load versus displacement diagram. To speed up rivet failure, a new set of parameters was obtained $\left(f_{C}=\right.$ 0.03 and $\left.f_{F}=0.04\right)$. These kinds of parameters are not deemed to be physically realistic $\left(f_{C}<f_{N}\right.$ and $\left.f_{F} \leqslant f_{N}\right)[2,11,14]$.

The variables are not very sensitive to the rivet material nucleation and growth parameters. They are mainly sensitive during the plastic step of the rivet and partially influential on the variables. Nevertheless, it is necessary to correctly identify the sensitive parameters of these two steps in the damage process. It was decided to opt for global optimization of the Gurson damage model under constraint, in order to limit the optimization cost (a function of the identified parameter number). The parameter vector $\underline{z}=\left(q_{2}, f_{N}, S_{N}, \varepsilon_{N}, f_{C}, f_{F}\right)$ is identified where: $f_{C}=f_{N}$ and $f_{F}=F\left(f_{C}\right)=F\left(f_{N}\right)$. The parameter vector $\underline{z}_{0}=(1.0,0.04,0.1,0.2)$ initialized the optimization process. The solution obtained was $\underline{z}_{1}=(1.5,0.045,0.075,0.15,0.045,0.055)$. The FE model's results correctly describe the experimental diagrams and displacement at failure (Fig. 13). The last part of the FE diagram is disturbed by numerical instabilities due to the elimination of solid elements and to the contact interface acting between the rivet and the hole.

\section{Validation of optimized parameters}

The Gurson damage model parameters were identified for both materials (2024-T351 and 7050) using simplified FE models. First it was necessary to verify that the complete FE models (whose results were used as reference for determining a simplified FE model for the optimization process) with the identified parameters gave satisfactory results compared with the experimental data.

A first model was computed with quasi-static imposed velocity $\left(0.5 \mathrm{~m} . \mathrm{s}^{-1}\right.$ for computing cost $)$. This first model corroborated (for both materials and both FE models) the experimental data from a global and a local viewpoint (load and local strain versus displacement diagrams).

A second model was then computed using the same FE models and the same identified Gurson damage parameters with a fixed imposed velocity of $10 \mathrm{~m} . \mathrm{s}^{-1}$. This verified the dynamic insensitivity of the observed diagrams. A late displacement at failure was observed when compared with the quasi-static behavior (Fig. 14).

Dynamic effects mainly concern the strain rate sensitivity of the material constitutive models, inertia effects and wave propagation along the specimen. Quasi-static and dynamic experiments were carried out to measure the strain rate sensitivity of both aluminum alloys [5]. The results showed no sensitivity, and constitutive models were chosen independently of the strain rate (power model). Moreover, the nucleation evolution (Gurson damage model) was controlled with effective plastic strain. It was also independent of the strain rate. The specimen mass (about $5 \mathrm{~g}$ ) was too small to introduce inertia effects. Wave propagation effects can lead to a time difference between load and displacement responses (measured at two different positions). The wave propagation velocity can be expressed by relation (7).

$$
c=\sqrt{\frac{E}{\rho}}
$$

where $E$ represents the material Young's modulus and $\rho$ is the density.

For an aluminum alloy, the wave propagation velocity is about $c=5140 \mathrm{~m} . \mathrm{s}^{-1}$. The equivalent time step $\Delta t_{\varphi}$ to cover the specimen length $(40 \mathrm{~mm})$ is about $\Delta t_{\varphi}=8.010^{-3} \mathrm{~ms}$. This corresponds to a displacement of about $\Delta \delta_{\varphi}=8.010^{-2} \mathrm{~mm}$. The dynamic behavior was then close to the quasi-static behavior when the displacement was corrected by $\Delta \delta_{\varphi}$ (Fig. 14). The 


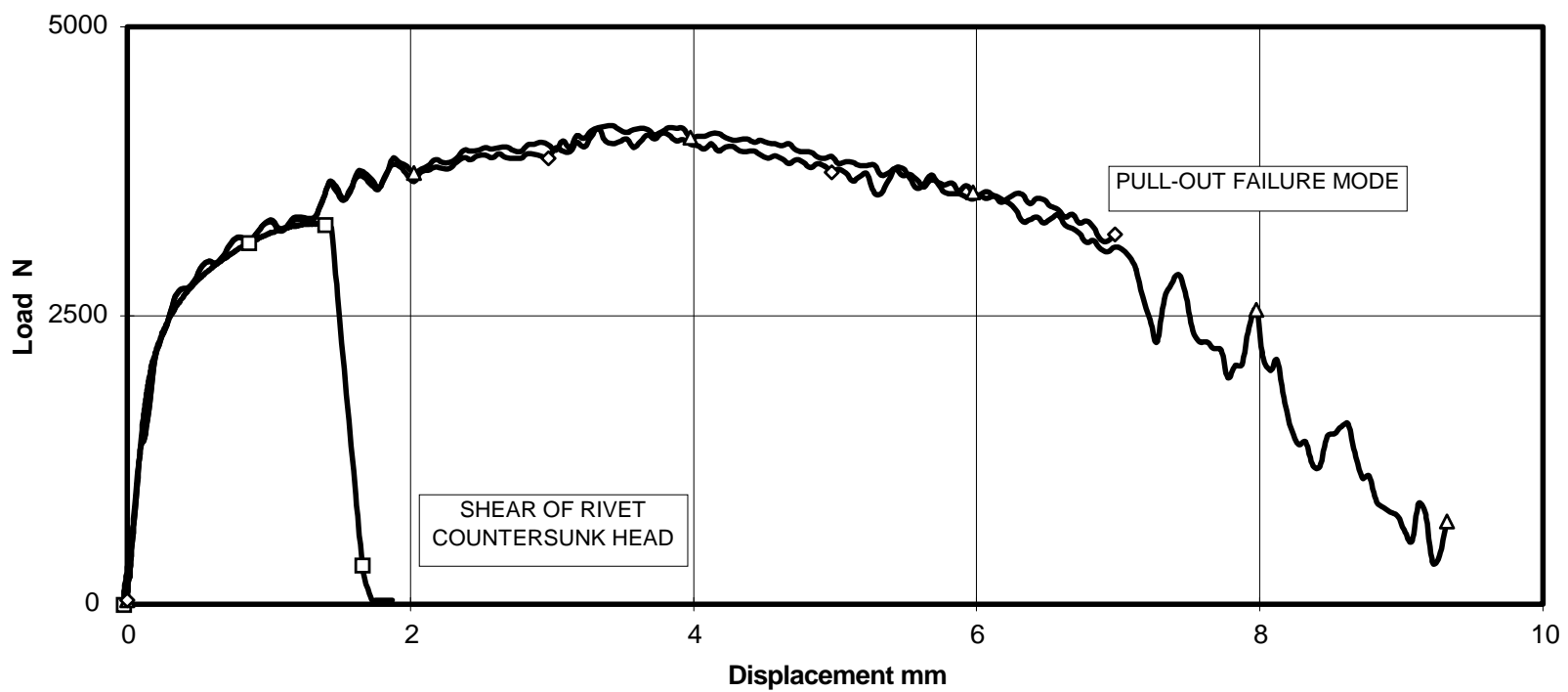

$\neg$ Experiment $\triangle$ Elastic/Plastic behaviour $\sim$ Reference damage parameters

Fig. 12. Load vs. displacement diagram - Single lap riveted joint shear specimens.

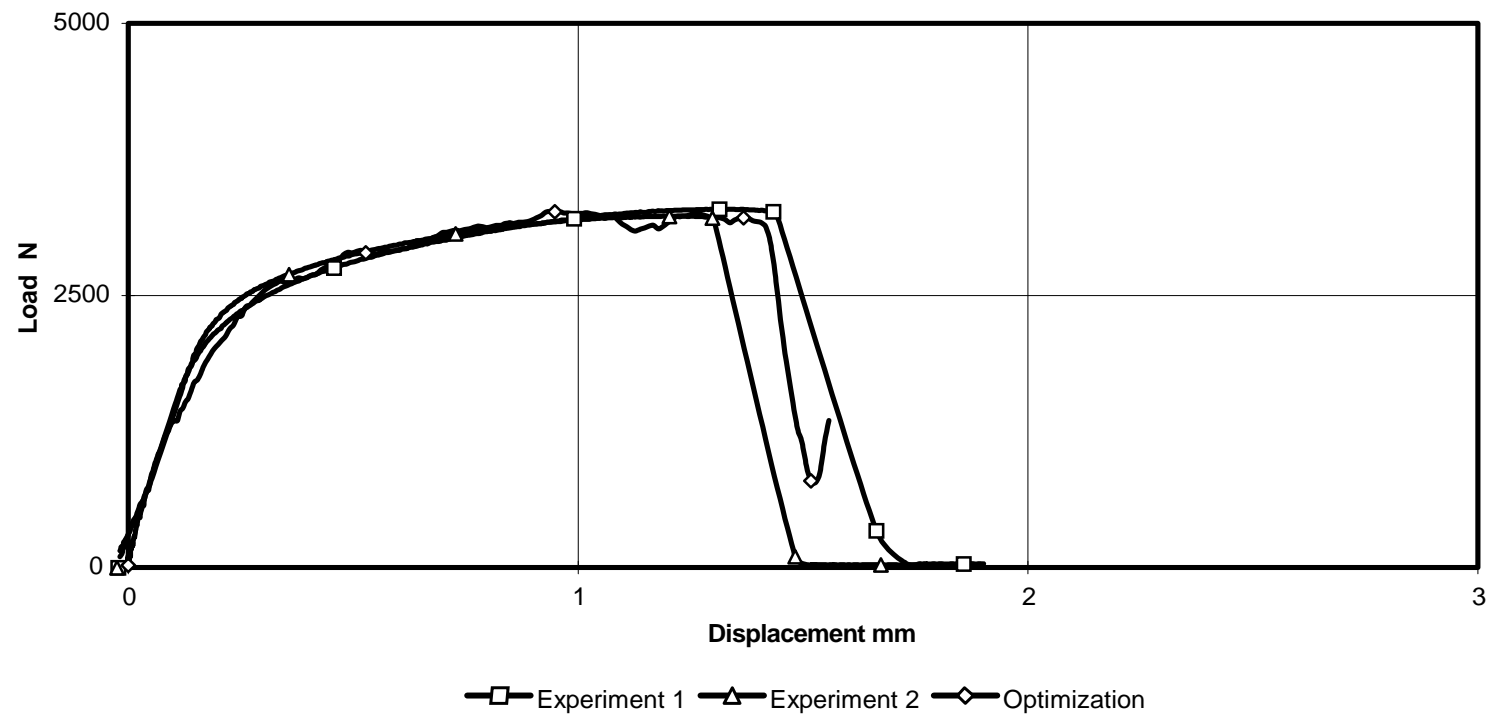

Fig. 13. Comparison of experimental and numerical results. (Single lap riveted joint shear specimens -7050 aluminium alloy).

same is true for the local strain when the time step is determined as a result of the gauge position.

Other models were computed to confirm that the optimized Gurson parameters were intrinsic. These models are presented below.

\subsection{4-T351 aluminum alloy (sheet metal plates)}

To evaluate the intrinsic nature of the optimized sheet metal plate material parameters (2024-T351), an FE model of a uniaxial tensile test specimen was computed [5]. The specimen was modeled with 8320 porous solid finite elements. The results of the quasi-static FE model are the same as the global experimental results (load versus displacement diagram, Fig. 15) and local experimental results (load versus local strain diagram, Fig. 16). Material constitutive models illustrate a mean behavior between the parallel and orthogonal roll direction of the sheet metal plate. Another model was computed with a dynamic imposed veloci- 


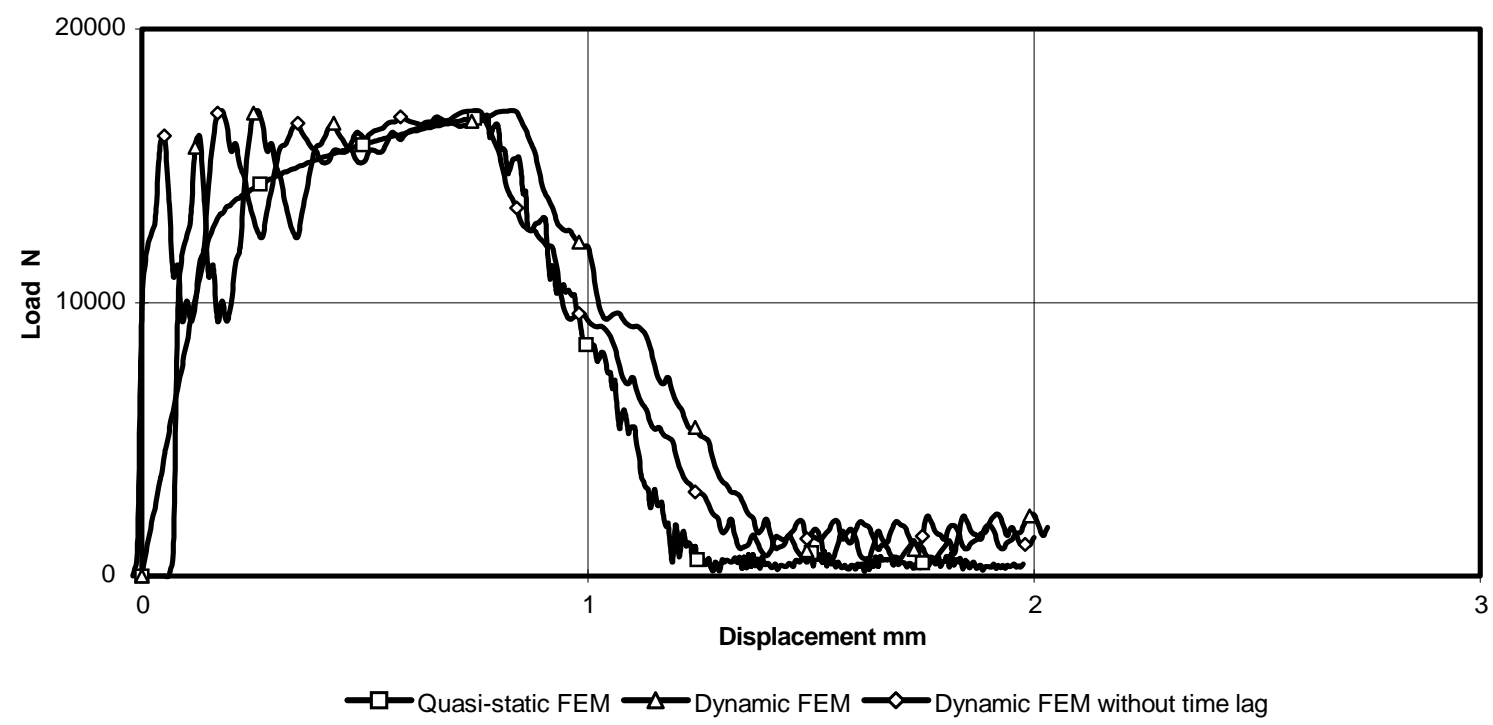

Fig. 14. Quasi-static and dynamic punched tension specimen FE model - Load vs. displacement diagram.

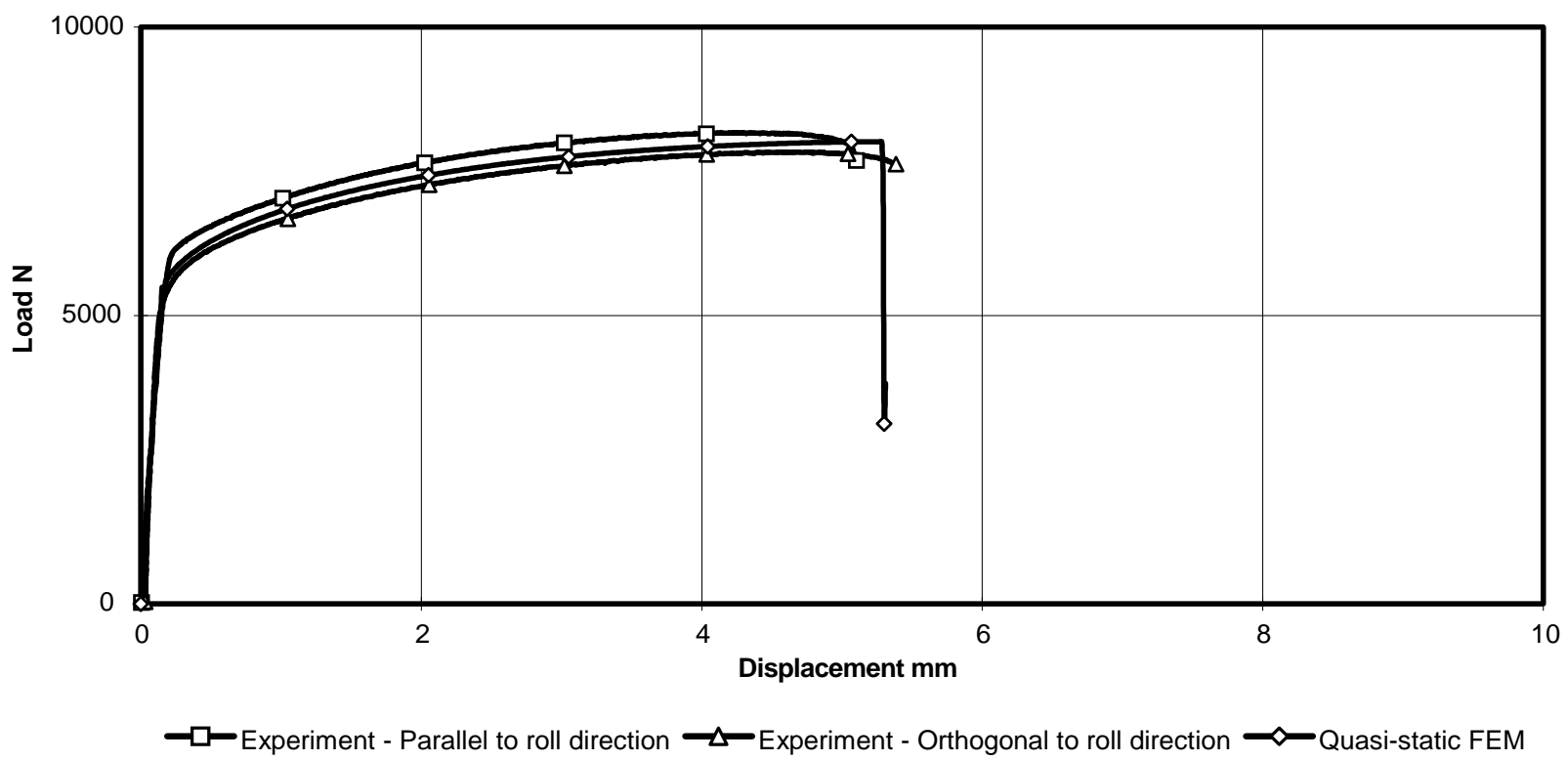

Fig. 15. Load vs. displacement diagram - Uniaxial tensile specimen.

ty $\left(V_{\mathrm{imp}}=10 \mathrm{~m} \cdot \mathrm{s}^{-1}\right)$. The results were the same as those of the experiment and the quasi-static FE model (discounting the time step).

As a study of sensitivity to mesh refinement, models (of elementary punched and uniaxial tensile test specimens) were computed with increased mesh density (reference mesh $\times 4$ ) or reduced mesh density (reference mesh / 8). The main difference concerned the displacement at ductile failure which was $3 \%$ lower than the reference solution given by experiment or the reference
FE model.

Models of both specimens were then computed with porous shell elements (type 115 in the PAM$\mathrm{CRASH}^{\mathrm{TM}}$ standard). The identified damage parameters of the 3D material law were directly used to model the material behavior of the 2D FE models. The results (obtained for different mesh densities) were close enough to the experimental data to preserve the parameters of the 3D material law. This proved that damage parameters (identified with 3D accurate FE mod- 


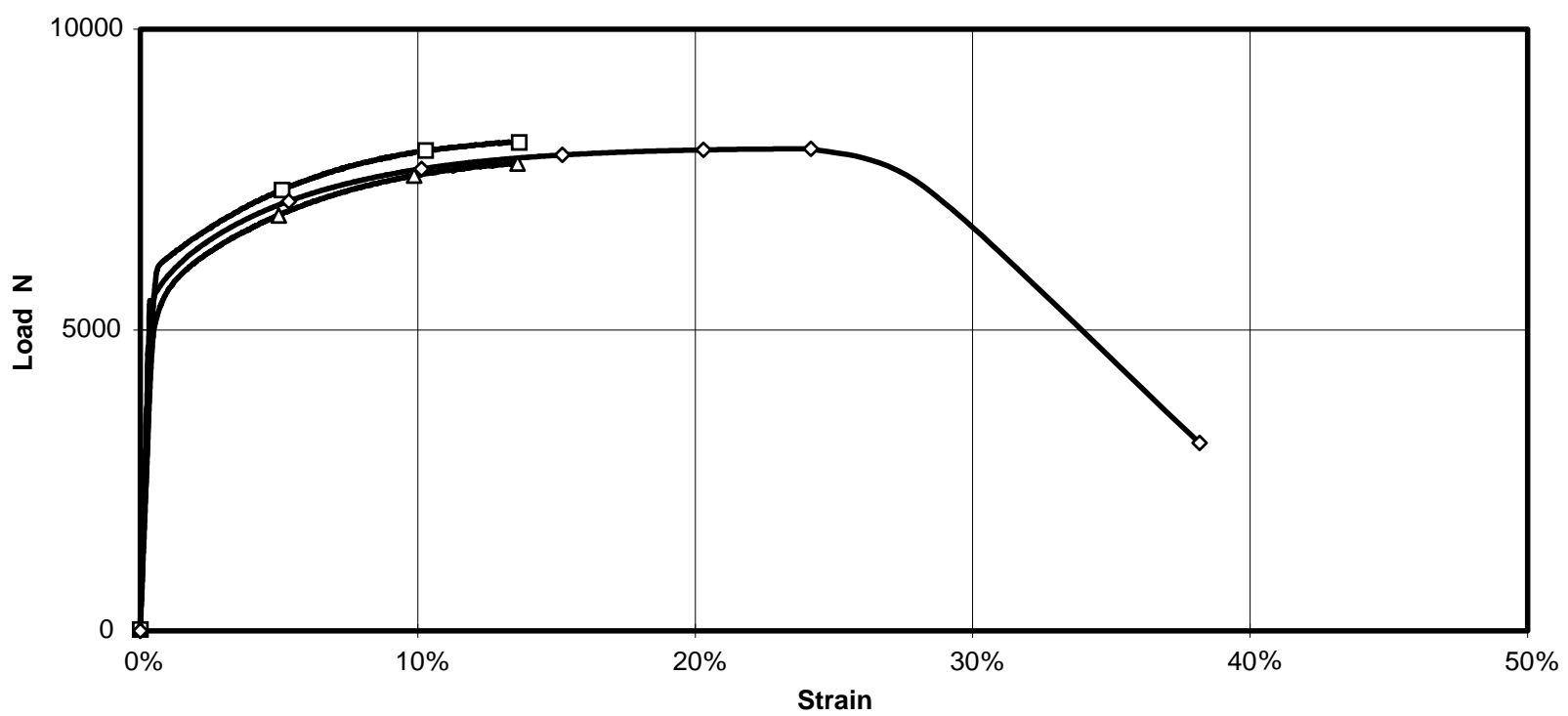

$\rightarrow \square$ Experiment - Parallel to roll direction $\triangle-$ Experiment - Orthogonal to roll direction $\leadsto$ Quasi-static FEM

Fig. 16. Load vs. local strain diagram - Uniaxial tensile specimen.

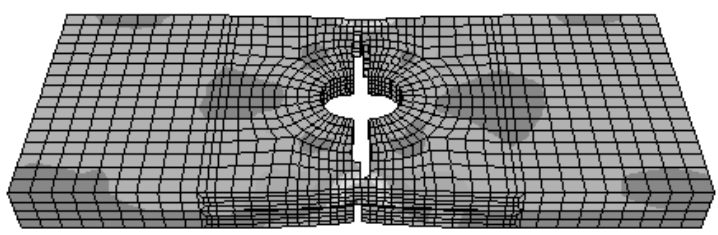

(a) Punched tension specimen (3D mesh)

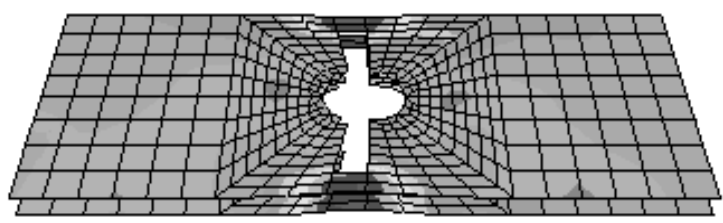

(b) 2D mesh with 3D material law

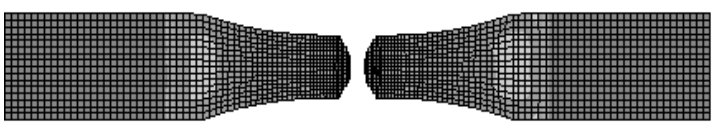

(c) Uniaxial tensile test specimen (3D accurate mesh)
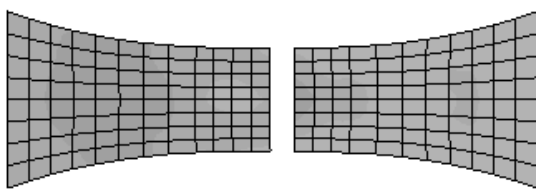

(d) 2D accurate mesh with 3D material law

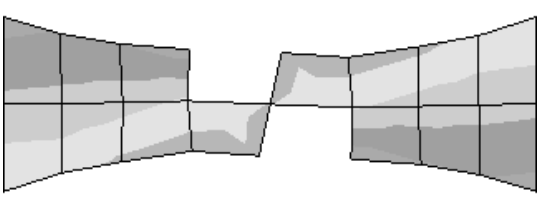

(e) 2D coarse mesh with 3D material law

Fig. 17. Von Mises equivalent stresses - Punched tension and uniaxial tensile test specimens.

els) are able to model material behavior for airframe crashworthiness.

Figure 17 presents the final von Mises equivalent stresses observed for the punched tension specimen and the uniaxial tensile test specimen.

\subsection{0 aluminum alloy (rivet)}

In parallel with the use of the single lap riveted specimens, an ARCAN type test rig and procedure was de- veloped. The ARCAN test procedure [1] was modeled to evaluate the intrinsic nature of the optimized parameters for the rivet (7050). The aim of this test was to proceed to combined tension and shear loading (Fig. 18). The ARCAN test may be a good alternative for optimizing damage parameters for the rivet material. In effect, there is no participation of the sheet metal plates in the response. However this experimental test is difficult to implement. Moreover, the cost of the computer model for the ARCAN test is too high to sat- 


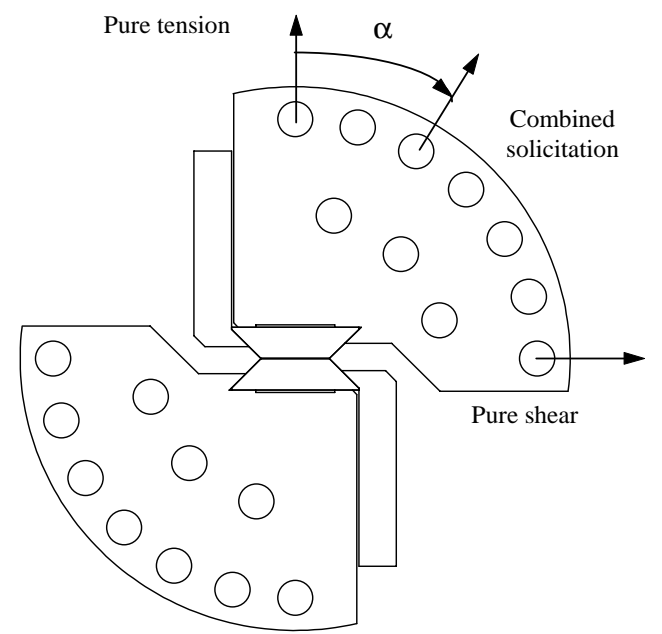

(a) Experimental set-up

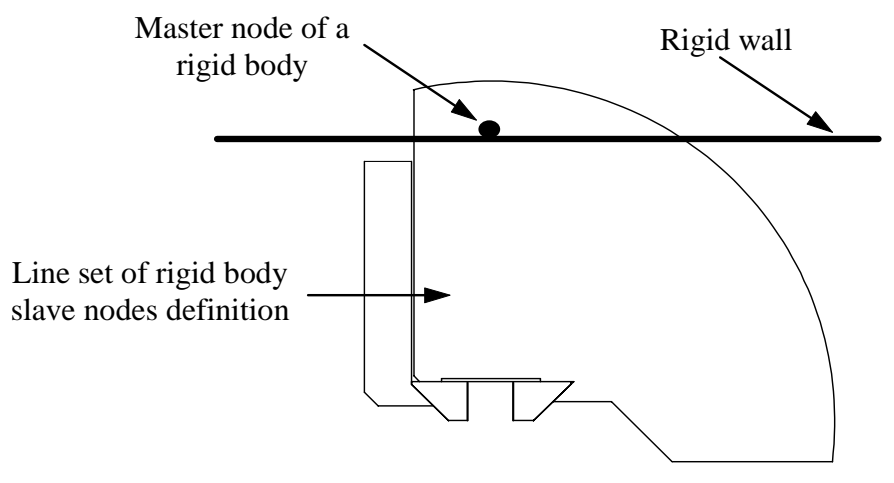

(b) FE modelling

Fig. 18. ARCAN test procedure.

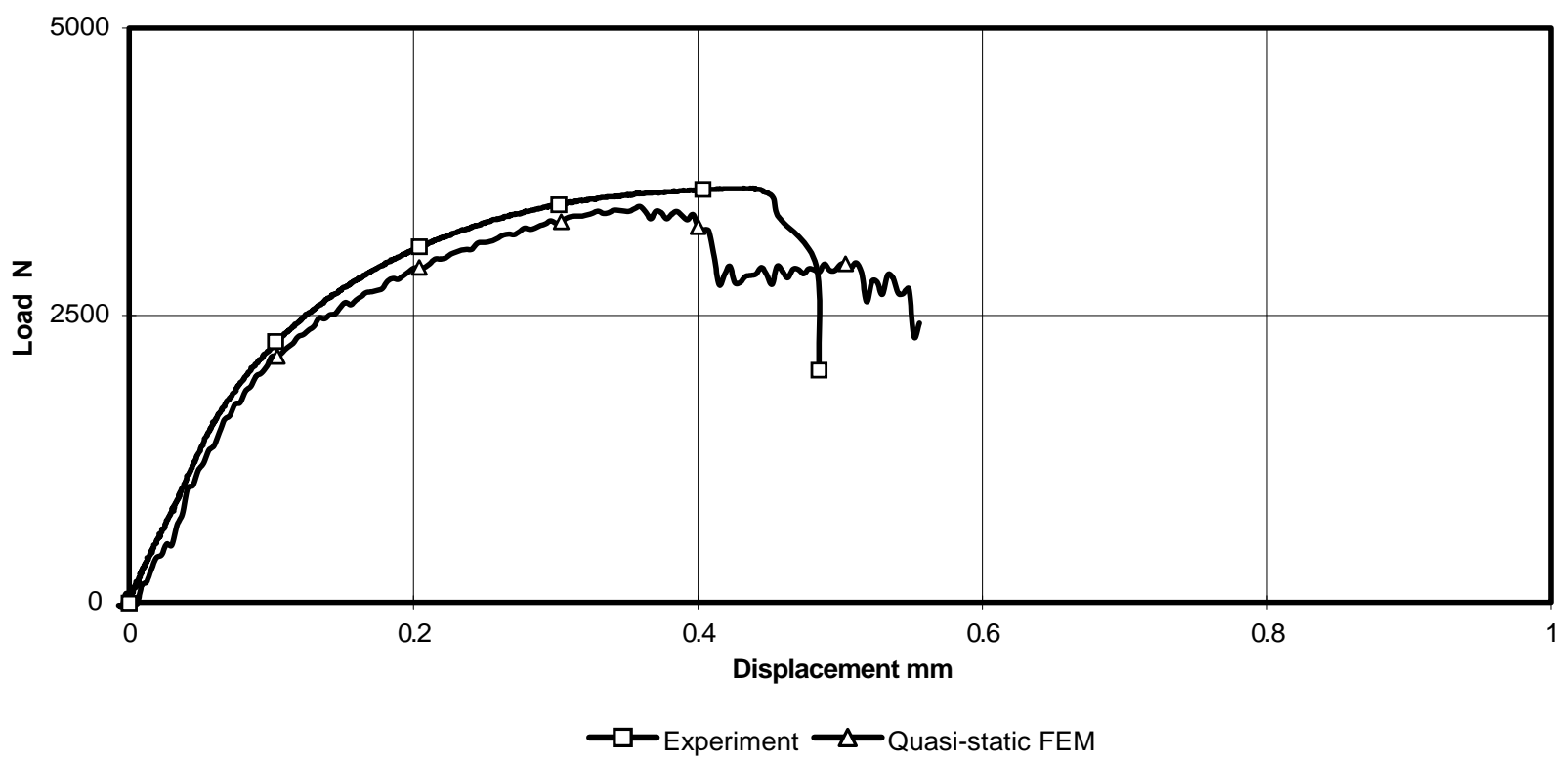

Fig. 19. Load vs. displacement diagram - ARCAN test in pure tension.

isfy a parameter identification procedure by an inverse method. Our objective is to show the capability of this procedure on the basis of experimental tests which are easy to perform. That is why the single lap riveted joint shear specimen was used to optimize the damage parameters of the rivet material.

The experimental set-up was completely modeled in order to correctly reproduce loading and boundary conditions: both steel disk quarters (oil hardening steel) orientating the load (experimental set-up), both hardening steel heels linking the experimental set-up to the riv- et, the rivet itself. Two rigid bodies were defined with a steel disk quarter and a heel (Fig. 18). Each rigid body master node was moved by a "rigid wall". Rigid walls were chosen as moving tied infinite planes with infinite mass and finite imposed velocity $\left(V_{\mathrm{imp}}=0.5 \mathrm{~m} . \mathrm{s}^{-1}\right)$. The definition of rigid wall does not allow free displacement of the slave node (that is to say the rigid body master node). The experimental set-up and heel were modeled by elastic-plastic solid elements. The rivet was modeled by porous solid elements. The contact between rivet, punched hole and heel was controlled 
by a self-impacting contact interface with finite friction $\left(k_{f}=0.2\right)$.

The FE model was finally made up of 21,818 solid elements. Residual riveting process stresses and strains were taken into account as the initial state of the tension simulation. The test modeled for this validation step was a pure tension test. The FE model results and the experimental results are compared in terms of the load versus displacement diagram (Fig. 19). The FE model correctly predicted the load versus displacement response, the displacement at failure and the failure mode (plunger puncture of the rivet countersunk head). Figure 20 presents the final von Mises equivalent stresses observed for the single lap riveted joint shear specimen and the final equivalent plastic strains observed for the ARCAN specimen.

\section{Conclusion}

This paper discusses the experimental and numerical characterization of dynamic failure models for riveted assemblies. Quasi-static and dynamic experiments were carried out on elementary punched tension specimens (2024-T351) and single lap riveted joint shear specimens (7050). The results did not show any strain rate sensitivity on the global and local experimental responses, although strain rates of about $500 \mathrm{~s}^{-1}$ to $7000 \mathrm{~s}^{-1}$ were measured. Gurson damage model parameters were identified for both aluminum alloys by an inverse method. The correlation between the FE and experimental results is good. To evaluate the intrinsic nature of the identified parameters, FE models were computed on:

- A uniaxial tensile test for the sheet metal plate (2024-T351 aluminum alloy)

- An ARCAN specimen in pure tension for the rivet (7050 aluminum alloy).

The results (obtained for low or high mesh density, 2D or 3D FE models) lead to good correlation between numerical and experimental behaviors for both specimens and prove that the identified parameters are quasi-intrinsic to the materials.

The results obtained from quasi-static and dynamic experiments and modeling show the feasibility of numerical databases. It is now possible to complete the numerical database by varying the riveted joint characteristics (e.g. bonding shape, edge margin, pitch). The FE numerical tool is therefore a design tool which can solve problems related to limit-design or design of a new riveted joint more rapidly and cost-effectively than experiments. In effect, experimental characterization requires a minimum of:

$$
K \cdot n \cdot C \cdot S \cdot P R(a, P, N, \text { etc. }) \text { experiments, }
$$

where:

- $K$ is the number of tests (performed with the same experimental set-up; $K \geqslant 3$ ) required to obtain statistically significant values

$-n$ is the number of fixed velocities (quasi-static $\rightarrow$ dynamic)

$-C$ is the type of riveted joint (e.g. row, chain, staggered)

$-S$ is the type of loading

$-P R$ is a function of the riveted joint parameters (e.g. edge margin $a$, pitch $p$, number of rivets $N$ ).

For two materials (sheet metal plate and rivet materials), the numerical database requires :

$$
\begin{aligned}
& 2 \cdot K \cdot n \underline{\text { experiments }} \begin{array}{l}
\text { (for experimental } \\
\text { characterization) }
\end{array} \\
& + \\
& K \cdot n \cdot C \cdot S \cdot P R(a, p, N, \text { etc. }) \text { FE modelings. }
\end{aligned}
$$

The gain obtained when:

$$
K \cdot n \cdot C \cdot S \cdot P R(a, p, N, \text { etc. }) \text { experiments }
$$

are replaced by:

$$
K \cdot n \cdot C \cdot S \cdot P R(a, p, N, \text { etc. }) \text { FE modelings, }
$$

more than justifies the cost of the experimental characterization for the two materials.

This material characterization of the riveted joint by numerical database allows numerical identification of the parameters of a macroscopic failure criterion dedicated to rivet representation for airframe crash modeling. FE tools can also solve problems linked to limitdesign or the design of new riveted assemblies more rapidly and cost-effectively than experiments.

\section{Acknowledgments}

This research was carried out with an ONERA grant (operation numbers 97207 and 98216) under the responsibility of Dr. P. Geoffroy, manager of the ONERA/MSE department. The authors are grateful to the ESI Group for the PAM-CRASH ${ }^{\mathrm{TM}}$ FE code and the company Dassault Aviation. The authors also wish to give special thanks to Dr. F. Lauro, for his valuable remarks which significantly contributed to this paper. 


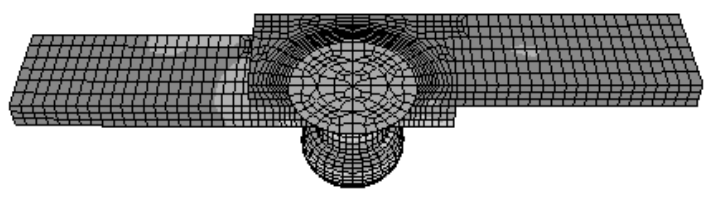

(a) Initial state from riveting FE modelling

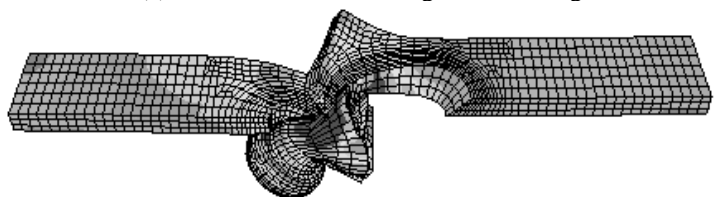

(b) Pull-out failure mode (without damage behaviour)

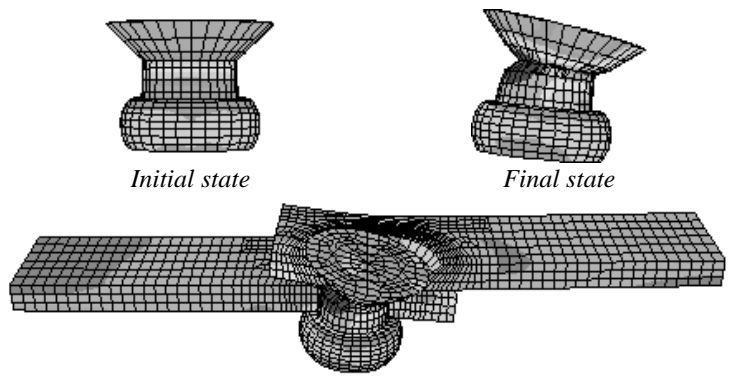

(c) Head shearing failure mode (with optimised damage parameters)

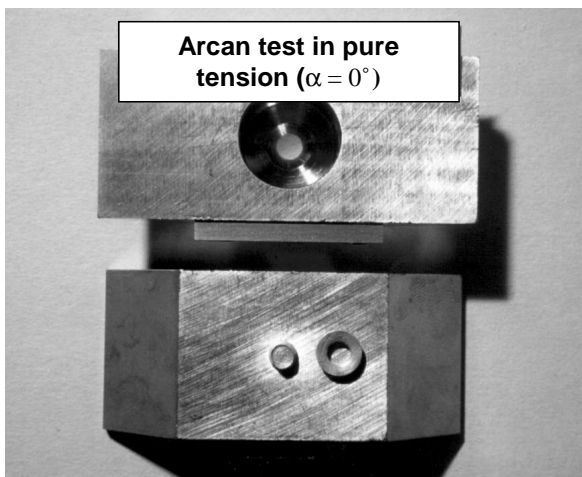

(d) Experimental pattern (ARCAN test in pure tension)

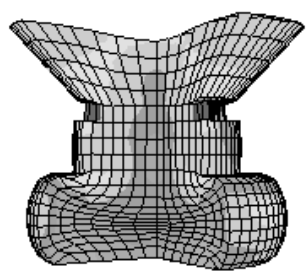

(e) FE pattern (ARCAN test in pure tension)

Fig. 20. Equivalent von Mises stresses - Single lap shear specimen and ARCAN specimen in pure tension.

\section{Appendix. Gurson damage model}

The constitutive damage model is based on description of void nucleation, growth and coalescence. The evolution of microstructural damage is represented by the current void volume fraction $f$ defined by relation (A.1).

$$
f=\frac{V_{a}-V_{M}}{V_{a}}
$$

$V_{a}, V_{M}$ are the elementary apparent volume of the material and the corresponding elementary volume of the matrix respectively. At the outset, $f$ is set to the initial void fraction volume $f_{I}$. The increase in the void fraction volume, $\Delta f$, is given by relation (A.2) in which $\Delta f_{N}$ and $\Delta f_{G}$ are respectively the increase of the nucleation and the growth void volume fraction.

$$
\Delta f=\Delta f_{N}+\Delta f_{G}
$$

The increase in the nucleated void volume, $\Delta f_{N}$, is related to the effective plastic strain, $\varepsilon_{M}$, in the case of a Gaussian distribution of the inclusions or second phase particles by relation (A.3).

$$
\Delta f_{N}=\frac{f_{N}}{S_{N} \cdot \sqrt{2 \pi}} e^{-\frac{1}{2}\left(\frac{\varepsilon_{M}-\varepsilon_{N}}{S_{N}}\right)^{2}} \cdot \Delta \varepsilon_{M}
$$

$f_{N}$ is the nucleated void volume fraction, $S_{N}$ represents the Gaussian standard deviation and $\varepsilon_{N}$ is the nucleated effective plastic strain.
The increase in the void fraction volume due to the growth of existing voids, is determined by requiring the matrix material to be plastically incompressible. The plastic incompressibility relation leads to relation (A.4).

$$
\Delta f_{G}=(1-f) \operatorname{tr} D^{P}
$$

$\operatorname{tr} D^{P}$ is the first invariant of the macroscopic plastic strain rate tensor.

The viscoplastic flow of the porous materials is described by the potential according to relations (A.5) and (A.6).

$$
\begin{aligned}
\Omega_{\mathrm{evp}}= & \frac{\sigma_{e q}^{2}}{\sigma_{M}^{2}}+2 \cdot q_{1} \cdot f^{*} \cdot \cos h\left(\frac{3}{2} \cdot q_{2} \cdot \frac{\sigma_{m}}{\sigma_{M}}\right) \\
& -\left(1+q_{3} \cdot f^{* 2}\right) \quad \text { with } \quad \sigma_{m}>0 \text { (A.5) } \\
\Omega_{\text {evp }}= & \frac{\sigma_{e q}^{2}}{\sigma_{M}^{2}}+2 \cdot q_{1} \cdot f^{*}-\left(1+q_{3} \cdot f^{* 2}\right) \\
& \text { with } \quad \sigma_{m} \leqslant 0
\end{aligned}
$$

In the above relations, $\sigma_{e q}$ is the von Mises equivalent stress (for an isotropic material) described in its deviatoric forms by $\sigma_{e q}=\sqrt{3 / 2 \cdot s_{i j}: s_{i j}}, \sigma_{M}$ represents the elastic-viscoplastic flow stress of the matrix, $\sigma_{m}$ is the hydrostatic stress, $q_{1}, q_{2}$ and $q_{3}=q_{1}^{2}$ are material parameters which characterize the void shape and volume and $f^{*}$ is the specific coalescence function 
obtained from relations (A.7) and (A.8).

$$
\begin{gathered}
f^{*}=f \quad \text { when } \quad f \leqslant f_{C} \\
f^{*}=f_{c}+\frac{f_{u}-f_{C}}{f_{F}-f_{C}}\left(f-f_{C}\right) \\
\text { when } \quad f>f_{C}
\end{gathered}
$$

$f_{C}$ is the critical void fraction volume at coalescence onset, $f_{F}$ is the critical void fraction volume at ductile fracture occurrence and $f_{u}$ is defined as $f_{u}=f^{*}\left(f_{F}\right)$.

The complete loss of stress-carrying capacity is obtained when $f$ exceeds the critical value $f_{F}$ and provokes ductile fracture. The inclusion of the Gurson damage model in the PAM-CRASH ${ }^{\mathrm{TM}} \mathrm{FE}$ code is described in more detail by Lauro et al. [7].

\section{References}

[1] L. Arcan, M. Arcan and I.M. Daniel, SEM fractography of pure and mixed mode interlaminar fracture in Graphite/Epoxy composites, ASTM Special Technical Publications 948 (1987), 41-47.

[2] R. Becker, A. Needleman, O. Richmond and V. Tvergaard, Void growth and failure in notched bars, J. Mech. Phys. Solids 36 (1988), 317-351.

[3] E.F. Bruhn, Analysis and design of fight vehicle structures, Jacobs Publishing Inc., 1973.

[4] A.L. Gurson, Continuum theory of ductile rupture by void nucleation and growth. Part I: Yield criteria and flow rules for porous ductile media, J. Engng. Mate. Tech. ASME 99 (1977), $2-15$.

[5] B. Langrand, Experimental characterization of 2024-T351 and 7050 aluminum alloys. ONERA-Lille/DMSE/RCS technical report $n^{\circ}$ 97/54, 1997.

[6] B. Langrand, P. Geoffroy, J.-L. Petitniot, J. Fabis, E. Markiewicz and P. Drazétic, Identification technique of constitutive model parameters for crashworthiness modeling, Aerospace Science and Technology 3(4) (1999), 215-227.

[7] F. Lauro, B. Bennani, P. Drazétic, J. Oudin and X. Ni, Ductile damage and fracture finite element modeling of elastoviscoplastic voided materials, Computational Materials Science 7 (1997), 295-307.

[8] E. Markiewicz, B. Langrand, E. Deletombe, P. Drazétic and L. Patronelli, Analysis of the riveting process forming mechanism, Int. J. of Materials and Product Technology 13(3-6) (1998), 123-145.

[9] E. Polak, Computational methods in optimization, Mathematics in Sciences and Engineering 77, Academic Press, 1971.

[10] V. Tvergaard and A. Needleman, Analysis of cup-one fracture in a round tensile bar, Acta Metallurgica 32 (1984), 157-169.

[11] V. Tvergaard, Material failure by void growth to coalescence, Adv. Appl. Mech. 27 (1990), 83-151.

[12] United States Military Standard, Rivets, buck type, preparation for and installation of. Reference: MIL-R-47196A-NOTICE $1,1986$.

[13] United States Military Standard, Preparation for and installation of. Reference: MIL-STD-403C-14, 1992.

[14] X.P. Xu and A. Needleman, Simulations of ductile failure with two size scales of voids, Eur. J. A/Solids 10(5) (1991), 459-484. 

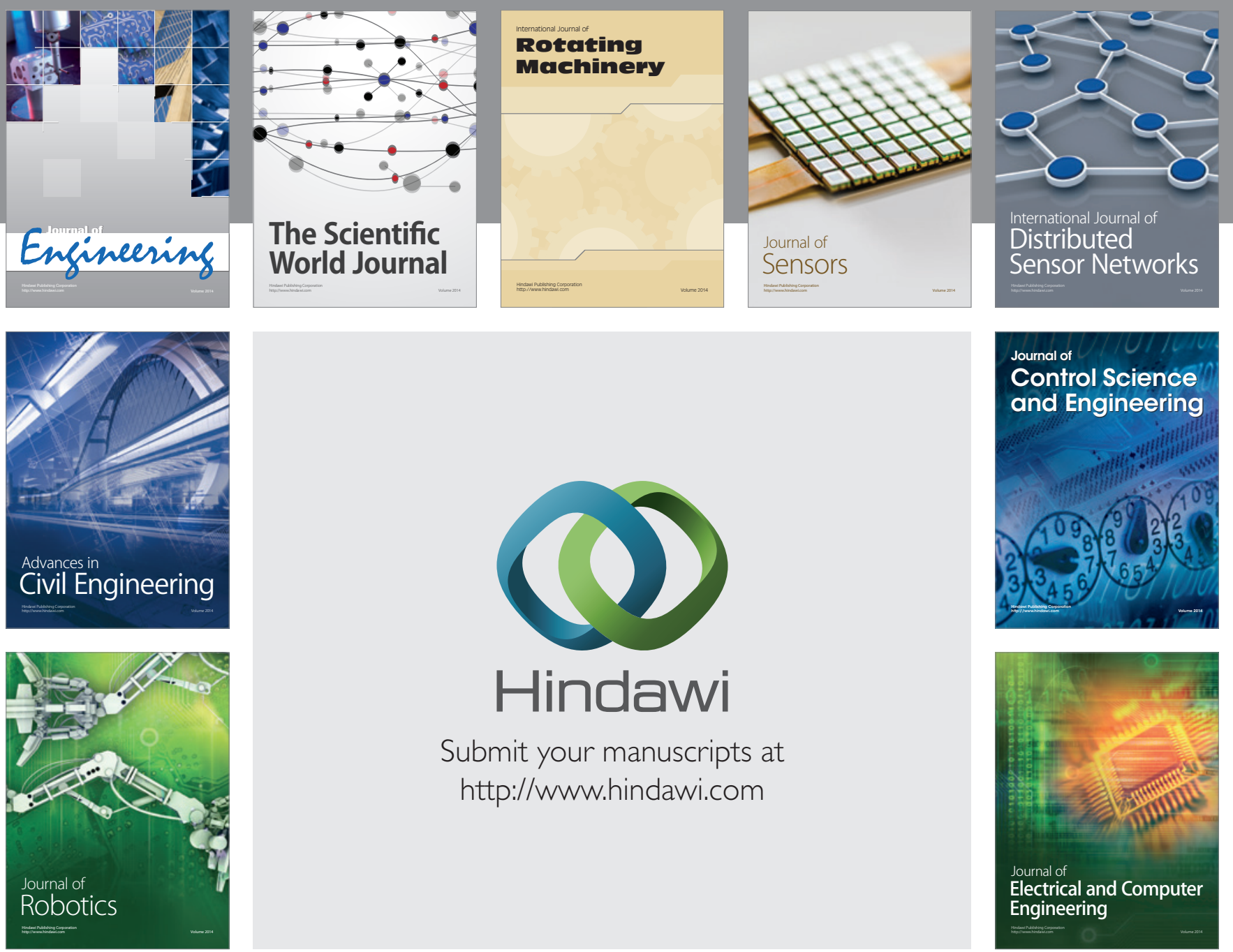

Submit your manuscripts at

http://www.hindawi.com
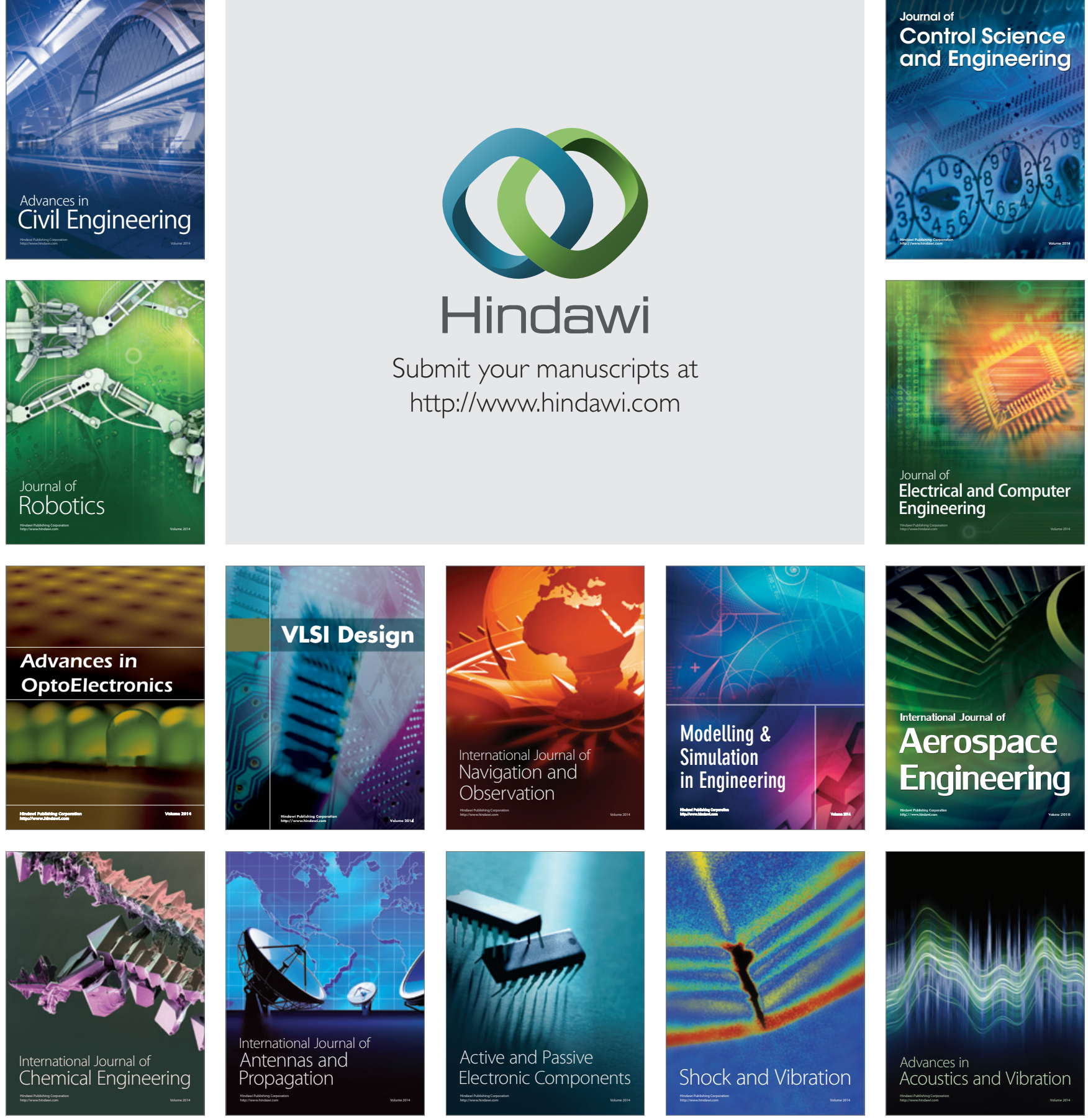